Article

\title{
Winter Irrigation Effects on Soil Moisture, Temperature and Salinity, and on Cotton Growth in Salinized Fields in Northern Xinjiang, China
}

\author{
Ling $\mathrm{Li}^{1,2}$, Hongguang Liu ${ }^{1,2, *}$, Xinlin $\mathrm{He}^{1,2}$, En Lin ${ }^{1,2}$ and Guang Yang ${ }^{1,2}$ \\ 1 College of Water Conservancy \& Architectural Engineering, Shihezi University, Shihezi 832000, China; \\ liling@stu.shzu.edu.cn (L.L.); hexinlin@shzu.edu.cn (X.H.); linen@stu.shzu.edu.cn (E.L.); \\ yangguang@shzu.edu.cn (G.Y.) \\ 2 Xinjiang Production \& Construction Group Key Laboratory of Modern Water-Saving Irrigation, \\ Shihezi 832000, China \\ * Correspondence: lhg123@shzu.edu.cn; Tel.: +86-0993-205-7229
}

Received: 10 August 2020; Accepted: 10 September 2020; Published: 14 September 2020

\begin{abstract}
Winter irrigation affected the movement of soil moisture, temperature, and salt, which was an effective improvement measure widely used in seasonal freeze-thaw areas. In this paper, we investigated the effects of different salinized cotton fields (mild salinization (S1), $5.15 \mathrm{~g} \cdot \mathrm{kg}^{-1}$; moderate salinization (S2), $8.17 \mathrm{~g} \cdot \mathrm{kg}^{-1}$; severe salinization (S3), $11.15 \mathrm{~g} \cdot \mathrm{kg}^{-1}$ ) and different winter irrigation rates (W0, $0 \mathrm{~m}^{3} \cdot \mathrm{hm}^{-2} ; \mathrm{W} 1,3000 \mathrm{~m}^{3} \cdot \mathrm{hm}^{-2} ; \mathrm{W} 2,3600 \mathrm{~m}^{3} \cdot \mathrm{hm}^{-2} ; \mathrm{W} 3,4200 \mathrm{~m}^{3} \cdot \mathrm{hm}^{-2}$ ) on soil moisture, temperature, salinity, and cotton growth in seasonal freeze-thaw areas. The results showed that the winter irrigation affected the temporal and spatial dynamics of soil moisture, temperature, and salinity, and the winter irrigation rate and degree of soil salinization were significantly correlated with soil moisture, temperature, and salinity $(p<0.01)$. Winter irrigation stabilized the soil temperature and reduced the freeze-thaw index of the soil. The heat conservation effect of winter irrigation increased with increasing winter irrigation rate and salinization degree, with the greatest effect on the freezing index of S2 and on the thawing index of S3. The soil water content and total salt concentration before spring tillage were significantly correlated with winter irrigation rate and degree of soil salinization $(p<0.05)$, and when the winter irrigation quota of different salinized cotton fields was greater than $3600 \mathrm{~m}^{3} \cdot \mathrm{hm}^{-2}$, the moisture content of soil layer $0-100 \mathrm{~cm}$ increased by more than $20 \%$, and the desalination reached over $40 \%$, compared with the values before winter irrigation. Winter irrigation improved the emergence rate and yield of cotton, with the soil salinization degree being significantly negatively correlated and winter irrigation rate significantly positively correlated with the emergence rate and yield of cotton fields in the following year $(p<0.01)$. Compared with the control treatment without winter irrigation, the average increases in cotton yield were W3 $(53.32 \%)$ $>$ W2 $(45.00 \%)>$ W1 $(29.36 \%)$. There was no significant difference in seedling emergence rate or yield between slightly and moderately salinized cotton fields under high winter irrigation rates (W2 and W3) $(p>0.05)$, although the seedling emergence rate and yield of severely salinized cotton fields increased significantly with increasing winter irrigation rate. In conclusion, winter irrigation proved to be a valuable treatment for severely salinized cotton fields, and the results of this study allowed us to determine the optimal winter irrigation rate for saline alkali cotton fields.
\end{abstract}

Keywords: winter irrigation; saline-alkali land; soil moisture content; soil temperature; soil salinity; cotton; emergence rate; yield 


\section{Introduction}

Xinjiang, in Northwest China, is located in the mid-latitude seasonal freeze-thaw zone, and its salinized soil area accounts for $22.01 \%$ of the total saline-alkali land area in China [1], which is the area with the widest distribution area and the heaviest soil salt concentration in China. According to the survey conducted by Xinjiang Institute of Ecology and Geography, Chinese Academy of Sciences in 2014 [2], the saline-alkali cultivated land in the Xinjiang irrigation area accounts for $37.72 \%$ of the cultivated land in the irrigation area, with an average annual increase in saline-alkali cultivated land of $0.26 \%$, with soil salinization becoming an increasingly serious problem. Freezing and thawing is a unique mechanism of soil salinization in seasonal freeze-thaw areas [3]; strong freeze-thaw action drives the water to migrate to the frozen surface of the soil surface, resulting in salt migration and accumulation from groundwater and deep soil layers to the surface layers [4]. It has been found that the rate of salt accumulation caused by soil freezing-thawing was about $30 \%$, and the annual salt accumulation rate of submembrane drip irrigation was about $14 \%$, in the absence of irrigation to achieve salt leaching during the non-growth period [5].

As the main cotton-producing area in China, Xinjiang's cotton output accounts for $84.90 \%$ of China's total [6]. The seedling emergence rate, quality, and yield of cotton are heavily affected by soil salinization [7]; when the soil salt concentration exceeded $0.58 \%$, the emergence rate of cotton was low and could even result in no yield [8]. The damage caused by soil salinization directly limits the sustainable economic development of the Xinjiang region [9-11].

Winter irrigation is a widely adopted improvement measure to treat soil salinization. Appropriate winter irrigation rates can effectively lower soil salinity, by leaching out the salt, reducing the migration of deep soil moisture and groundwater to the surface during the freezing process, and significantly inhibiting the accumulation of soil salt on the surface during the freezing-thawing period. Wu et al. [12] studied the water uptake mechanism by alfalfa under winter irrigation through stable isotope mixing model analysis, and the research results showed that alfalfa roots could take up soil water during heavy winter irrigation, but not in response to moderate or low winter irrigation rates. Winter irrigation was also shown to effectively improve the survival rate and yield of alfalfa in salinized soils. Li et al. [13] reported that winter irrigation could significantly improve the soil water content and temperature of desert oasis farmland in arid areas during the freeze-thaw period, effectively alleviating the impact of spring drought and promoting the growth and development of crops. Alexandra et al. [14] and Nira et al. [15] pointed out that winter irrigation could increase the nitrogen concentration in the soil solution, achieve soil microbial enrichment, and improve nitrogen supply and phosphorus utilization rate in late crop growth stages. Mu et al. [16] studied the effects of irrigation methods and winter irrigation rates on the soil water content, temperature, and salinity in cotton fields under drip irrigation in northern Xinjiang, and concluded that the effect on water content and salt leaching of a high rate of winter irrigation was particularly effective, with the optimum winter irrigation rate under drip irrigation mode being $3000 \mathrm{~m}^{3} \cdot \mathrm{hm}^{-2}$; under these conditions, the impact of winter irrigation on soil water and salt concentration could reach a depth of $300 \mathrm{~cm}$. Yang et al. [17] demonstrated that, as the winter irrigation rate increased, the soil salt leaching effect was enhanced, but irrigation water-use efficiency was reduced, with the optimal winter irrigation rates on cotton fields in southern Xinjiang being 1800-3600 $\mathrm{m}^{3} \cdot \mathrm{hm}^{-2}$. Liu et al. [18] applied winter irrigation to jujube (Ziziphus jujube) plantations in southern Xinjiang and reported that drip irrigation in winter at a rate of $3150 \mathrm{~m}^{3} \cdot \mathrm{hm}^{-2}$ could significantly increase soil water content and salt leaching, increase the survival rate of the jujube trees the following year, and promote their growth and development. The above studies showed that winter irrigation can increase soil water storage, inhibit soil temperature change, reduce soil surface salt content, promote soil microbial activities, indirectly change soil physical and chemical properties, and further affect crop growth in the next year. In general, winter irrigation has a significant effect on saline-alkali farmland management.

Winter irrigation has a beneficial effect on crops on salinized soil, by increasing soil water content and reducing the salt content. Previous studies have focused on how winter irrigation methods and 
rates affect soil moisture and salinity and on the subsequent physiological indexes of crops in the following year. However, experimental studies and production practices have shown that the effect of winter irrigation on soil moisture content was affected not only by winter irrigation rate and irrigation method, but also directly by the original salt concentration of the soil $[19,20]$. The effect of soil salt concentrations on the response to winter irrigation and the response of the physiological indexes of crops the following year have not been thoroughly studied. Currently, the optimal irrigation rate for winter irrigation in northern Xinjiang is still guided by experience rather than by research. The use of an inappropriate winter irrigation system has led to problems, such as inadequate leaching of salt from cotton fields or a serious waste of irrigation water. Therefore, it is important to determine the optimal winter irrigation rates for cotton fields with different levels of salinization.

Field experiments were conducted in the Shihezi Irrigation District of Xinjiang to study the optimal leaching rate for winter irrigation in cotton fields with different salinity levels in northern Xinjiang. In this experiment, the effects on soil water, temperature and salinity of cotton fields during the non-growth period in response to winter irrigation and leaching, as well as the seedling emergence and yield of cotton in the following year were monitored. The spatiotemporal variation in soil water, temperature and salinity in cotton fields under different winter irrigation rates were also analyzed. Through correlation analysis, the interactive effects on water, temperature and salt under winter irrigation was determined. Furthermore, the crop physiological indexes in each experimental group after winter irrigation treatment were analyzed by data fitting, to determine the optimal winter irrigation rate for cotton fields with different levels of salinity in northern Xinjiang.

\section{Materials and Methods}

\subsection{Experimental Site}

A field experiment was conducted from November 2018 to October 2019. The experimental site was located in Beiquan Town, Shizong General Field, 8th Division, Xinjiang Production and Construction Corps, Northwest China (latitude: $44^{\circ} 27^{\prime} 42^{\prime \prime}-44^{\circ} 27^{\prime} 53^{\prime \prime} N$, longitude: $85^{\circ} 59^{\prime} 00^{\prime \prime}-85^{\circ} 59^{\prime} 19^{\prime \prime}$ E; altitude: $308.80 \mathrm{~m}$; Figure 1). The experimental area has a typical temperate continental climate with an average annual temperature of $7.5-8.2^{\circ} \mathrm{C}$, annual rainfall of $180-270 \mathrm{~mm}$, and annual evaporation rate of $1723-2260 \mathrm{~mm}$. The annual frost-free period is $147-191 \mathrm{~d}$ and the annual sunshine duration is $2318-2770 \mathrm{~h}$. The soil layer depth of $0-100 \mathrm{~cm}$ was sandy loam soil with a $\mathrm{pH}$ value of 8.49 at the test site. The physical properties of soil in the test site are shown in Table 1 . The results showed that the saturated moisture content was $42.54 \%$, the field water-holding capacity was $31.56 \%$, and the soil porosity was $42.21 \%$. The groundwater depth in winter was more than $7.20 \mathrm{~m}$, and the groundwater salinity was $3.20 \mathrm{~g} \cdot \mathrm{L}^{-1}$.

Table 1. The physical properties of soil in the test site.

\begin{tabular}{cccccc}
\hline Soil Depth/cm & Soil Texture & Sand/\% & Silt/\% & Clay/\% & $\begin{array}{c}\text { Bulk } \\
\text { Density/(g.cm }\end{array}$ \\
\hline 0-20 & Sandy loam & 62.65 & 32.74 & 4.61 & 1.47 \\
$20-40$ & Sandy loam & 63.29 & 34.82 & 3.88 & 1.48 \\
$40-60$ & Sandy loam & 71.93 & 22.46 & 5.61 & 1.51 \\
$60-80$ & Sandy loam & 68.92 & 26.76 & 4.32 & 1.49 \\
$80-100$ & Sandy loam & 73.08 & 23.49 & 3.43 & 1.52 \\
\hline
\end{tabular}

Note: The content of soil particle size was determined by laser particle size analyzer (LS13320, Beckman Coulter, Shanghai, China), and the test results were analyzed according to the soil texture classification standard of USDA. The soil physical property index was the average value of the study area.

\subsection{Experimental Design}

The test area was $7.24 \mathrm{hm}^{2}$. The average salt content of the $0-100 \mathrm{~cm}$ soil layer in different strip fields was measured in the test area. According to the Soil Salinization Soil Classification Standard [21] 
and the measured results, the lightly, moderately and severely salinized areas were selected to set up the test plots. The experiment was set up in a completely randomized block trial, with two factors, winter irrigation rate, and soil salinization level. There were four winter irrigation rates: $0 \mathrm{~m}^{3} \cdot \mathrm{hm}^{-2}$ (control treatment without winter irrigation, W0), $3000 \mathrm{~m}^{3} \cdot \mathrm{hm}^{-2}$ (W1), $3600 \mathrm{~m}^{3} \cdot \mathrm{hm}^{-2}$ (W2), and $4200 \mathrm{~m}^{3} \cdot \mathrm{hm}^{-2}$ (W3). The background salt concentration of the three test areas was: $5.15 \mathrm{~g} \cdot \mathrm{kg}^{-1}$ (mild salinization, S1), $8.17 \mathrm{~g} \cdot \mathrm{kg}^{-1}$ (moderate salinization, S2), and $11.15 \mathrm{~g} \cdot \mathrm{kg}^{-1}$ (severe salinization, S3). As a result, there was a total of 12 treatments in the experiment (Table 2), each treatment being replicated three times, with 36 test plots being set up in total. The area of each plot was $50 \mathrm{~m}^{2}$ ( $5 \mathrm{~m}$ wide and $10 \mathrm{~m}$ long), and the adjacent plots were $3 \mathrm{~m}$ apart. Each treatment plot was separated by soil berms with a height of $40 \mathrm{~cm}$ and a width of $40 \mathrm{~cm}$. On November 1, 2018, the experimental area was set up in the field. Plastic film to a depth of $50 \mathrm{~cm}$ was laid on both sides of each soil berm to prevent water leakage and lateral penetration. On 4 November 2018, 36 soil moisture monitoring devices (Shang Crop Soil Monitor ET100, Insentek, Shenzhen, China) were set up, one in the center of each treatment plot. Controlled winter irrigation was carried out in each experimental plot from November 5 to 6, 2018. The field experiment layout is shown in Figure 1.

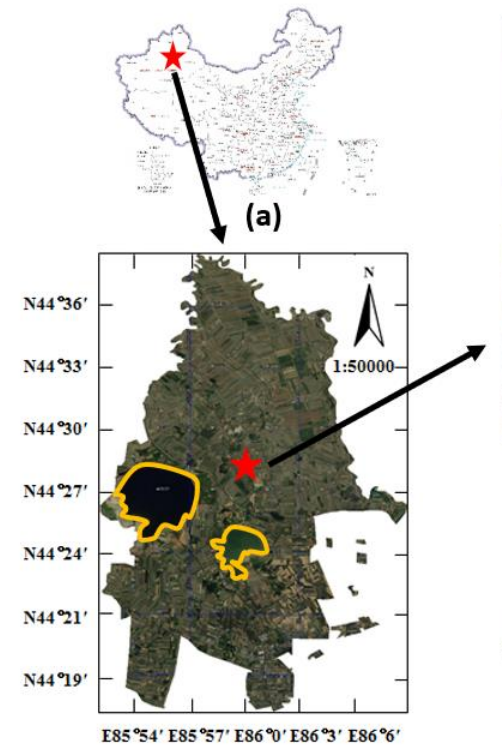

(b)

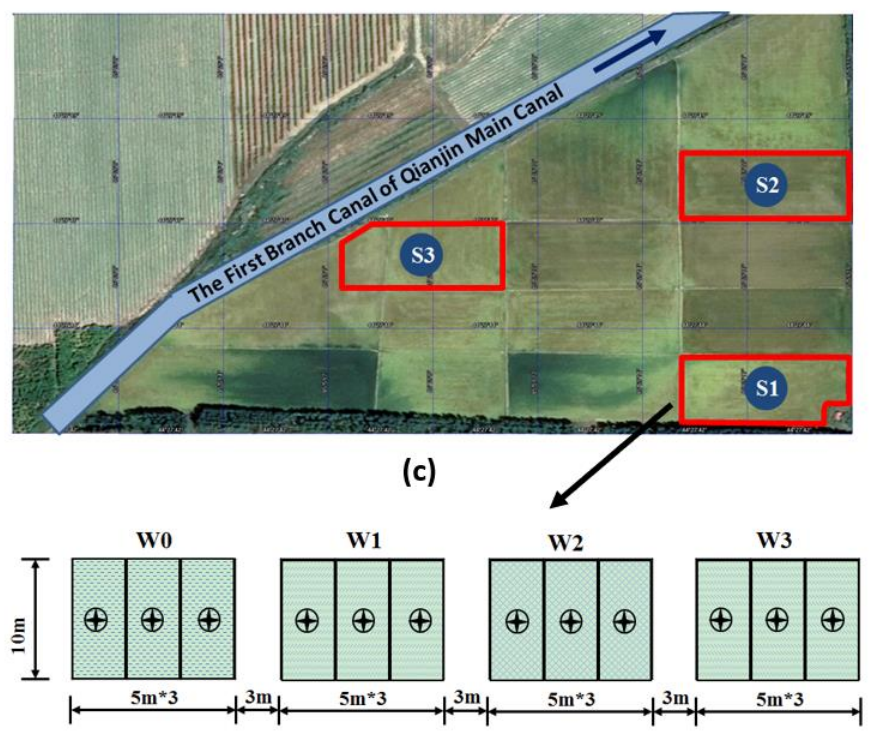

(d)

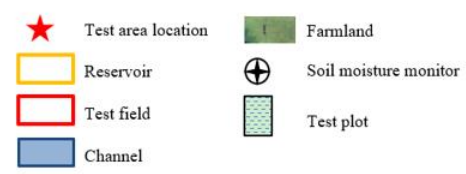

Figure 1. Location map of test area and layout of winter irrigation experimental area. (a) China; (b) Beiquan Town, Shizong General Field, 8th Division, Xinjiang Production and Construction Corps, Northwest China; (c) Test area; (d) Test plot layout of each salinization test area. The red five-pointed star represents the area indicated by the red arrow, the red polygonal area in the figure (c) is the test layout area, and the black circle in the figure (d) represents the Shang Crop Soil Monitor.

Cotton was planted in the winter irrigation experimental area in the year (2019) after winter irrigation, and the soil moisture monitoring equipment arranged in the test plots was retained. The cotton variety planted in the experimental area was 'Kangjiale 1671', using the cultivation technology of "one film, three pipes, and six rows", among which the row spacing was $66 \mathrm{~cm}+$ $10 \mathrm{~cm}$ (wide row + narrow row), the plant spacing was $11 \mathrm{~cm}$, and the plastic film width was $2.05 \mathrm{~m}$. Two films were laid in each experimental plot, and the mechanical seeding amount of cotton was $24 \mathrm{~kg} \cdot \mathrm{hm}^{-2}$. Cotton planting with drip irrigation under film is shown diagrammatically in Figure 2. The cotton management measures were consistent with local crop management methods. The fertilizer 
application in each plot was carried out simultaneously by drip irrigation, with the fertilizer dissolved in the irrigation water, according to the mass ratio of ammonium dipotassium phosphate to urea of 1:2, and the total fertilization amount was $1050 \mathrm{~kg} \cdot \mathrm{hm}^{-2}$ (Table 3). A total of 11 periods of drip irrigation was carried out over the entire crop growth period, with an irrigation rate of $6075 \mathrm{~m}^{3} \cdot \mathrm{hm}^{-2}$ (Table 3). The irrigation water for winter irrigation and growing period was well water, with the salinity of the irrigation water being $0.4-1.0 \mathrm{~kg} \cdot \mathrm{m}^{-3}$.

Table 2. Experimental design of winter irrigation rate and initial salt concentration.

\begin{tabular}{ccc}
\hline Treatment & Initial Salt Concentration/(g. $\left.\mathbf{k g} \mathbf{~}^{\mathbf{1}}\right)$ & Winter Irrigation Rate $/\left(\mathbf{m}^{\mathbf{3}} \cdot \mathbf{h m}^{\mathbf{- 2}} \mathbf{)}\right.$ \\
\hline W0S1 & 5.15 & 0 \\
W1S1 & 5.15 & 3000 \\
W2S1 & 5.15 & 3600 \\
W3S1 & 5.15 & 4200 \\
W0S2 & 8.17 & 0 \\
W1S2 & 8.17 & 3000 \\
W2S2 & 8.17 & 3600 \\
W3S2 & 8.17 & 4200 \\
W0S3 & 11.15 & 0 \\
W1S3 & 11.15 & 3000 \\
W2S3 & 11.15 & 3600 \\
W3S3 & 11.15 & 4200 \\
\hline
\end{tabular}

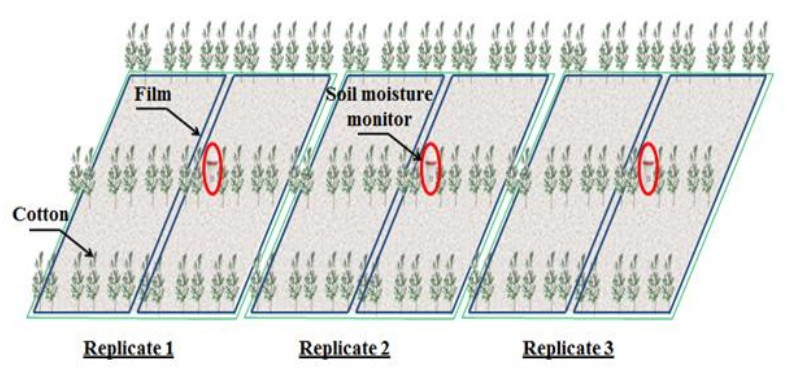

(a)

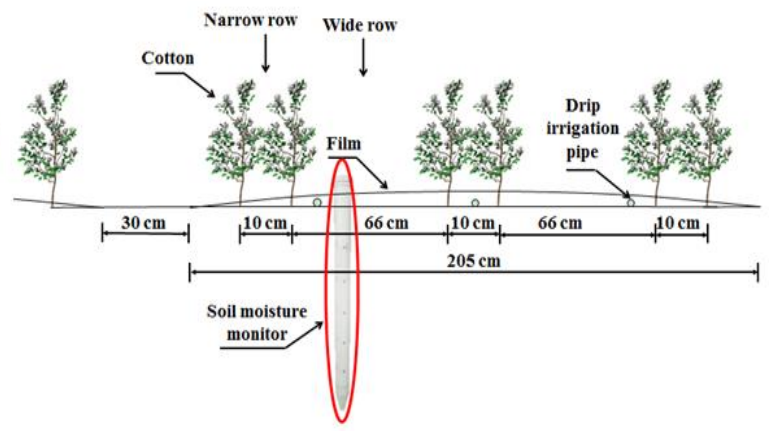

(b)

Figure 2. Drip irrigation under film for cotton planting. (a) Plan diagram. (b) Section diagram.

Table 3. Irrigation and fertilization schedule for cotton in the experimental area.

\begin{tabular}{|c|c|c|c|}
\hline Growth Stage & Irrigation Date/(mm.dd) & Irrigation Rate $/\left(\mathrm{m}^{3} \cdot \mathrm{hm}^{-2}\right)$ & Fertilization Rate/(kg.hm $\left.{ }^{-2}\right)$ \\
\hline \multirow{2}{*}{ Emergence } & $04.24-04.25$ & 600 & 0 \\
\hline & 05.03-05.05 & 525 & 110 \\
\hline \multirow[t]{2}{*}{ Seeding } & $05.23-05.25$ & 525 & 100 \\
\hline & $06.19-06.21$ & 600 & 110 \\
\hline \multirow[t]{3}{*}{ Budding } & $06.30-07.01$ & 525 & 100 \\
\hline & $07.10-07.12$ & 525 & 100 \\
\hline & $07.20-07.22$ & 600 & 110 \\
\hline \multirow{3}{*}{ Flower bol } & 07.31-08.02 & 525 & 100 \\
\hline & 08.09-08.11 & 525 & 110 \\
\hline & $08.17-08.19$ & 525 & 100 \\
\hline Boll-opening & $08.27-08.29$ & 600 & 110 \\
\hline
\end{tabular}




\subsection{Measurements}

\subsubsection{Soil Salinity}

During the experimental period from November 2018 to May 2019, soil samples from a depth of $1 \mathrm{~m}$ were collected with a soil auger from three locations within $20 \mathrm{~cm}$ of the soil moisture monitor in each test plot. Soil samples were collected from $0 \mathrm{~cm}$ (i.e. the soil surface), with one sample taken for every $10 \mathrm{~cm}$ soil layer, and 33 samples were taken from each experimental plot at a time. The specific soil sampling dates were November 5 (before winter irrigation), November 12 ( $7 \mathrm{~d}$ after the end of winter irrigation), November 20 (15 d after the end of winter irrigation), February 23 (the end of freezing), March 20 (snow-thaw period), and April 15 (before spring tillage).

The electrical conductivity value of saturated soil extract was measured using a digital conductivity meter (FE38-Standard, METTLER TOLEDO Corporation, Shanghai, China), and the drying residue method was used to calibrate the electrical conductivity value and converted it into the mass fraction of salt [20]. The relationship between soil salt concentration and electrical conductivity was converted into:

$$
S=4.9566 \times E C_{e}-0.1168\left(r^{2}=0.9795\right)
$$

where $S$ is the soil salt concentration, $\mathrm{g} \cdot \mathrm{kg}^{-1} ; E C_{e}$ is the conductivity value, $\mathrm{mS} \cdot \mathrm{cm}^{-1}$.

The equation to calculate the total amount of salt per unit area of soil $\left(1 \mathrm{~m}^{2}\right)$ at a certain depth (hereinafter referred to as the total salt content) [22] was:

$$
C=100 \times H \times \gamma \times S
$$

where $C$ is the total salt content of a soil layer of thickness $\mathrm{H}, \mathrm{g} ; H$ is the soil layer thickness, $\mathrm{cm} ; \gamma$ is the bulk density of soil, $\mathrm{g} \cdot \mathrm{cm}^{-3}$, with the calculation being based on the actual measured values in Table 1; $S$ is the soil salt concentration, $\mathrm{g} \cdot \mathrm{kg}^{-1}$.

\subsubsection{Soil Temperature and Soil Water Content}

The soil temperature and water content were determined using a Shang Crop Soil Monitor-ET100. The measurement range of soil temperature was $-20^{\circ} \mathrm{C} \sim 60^{\circ} \mathrm{C} \pm 0.50^{\circ} \mathrm{C}$ and the measurement range of soil volume moisture content was $0 \% \sim 100 \% \pm 4 \%$. The soil temperature and volume moisture content at depths of $0,10,20,30,40,50,60,70,80,90$, and $100 \mathrm{~cm}$ from the surface were measured by a Shang Crop Soil Monitor. The recording interval was five minutes, and the data were downloaded in real time.

The soil freeze-thaw index was calculated as follows [23]. The soil freeze-thaw index includes the freezing index and the thawing index, which refer to the cumulative value of temperatures less than $0^{\circ} \mathrm{C}$ and greater than $0^{\circ} \mathrm{C}$, respectively, over a specified period of time. The calculation period of the freezing index is from the beginning of freezing to the end of freezing, that is, from 15 November 2018 to 15 March 2019. The calculation period of the thawing index is from the end of freezing (15 March 2018) to the end of thawing (20 April 2019).

The calculation equation of soil water storage capacity [13] was:

$$
M=10 \times H \times W_{S}
$$

where $M$ is the soil water storage capacity, $\mathrm{mm} ; H$ is the soil layer thickness, $\mathrm{cm} ; W_{S}$ is the soil volumetric water content, $\%$.

\subsubsection{Seedling Emergence Rate and Crop Yield}

After the completion of seeding, seedling emergence counts were carried out in each plot $15 \mathrm{~d}$ after the first irrigation, that is, in mid-May 2019. The number of cotton seedlings over a row length of $1 \mathrm{~m}$ under film near the soil moisture monitor in each experimental plot was counted, and this was 
repeated three times in each plot. The average value was taken to obtain the actual seedling emergence rate of each treatment. The equation for seedling emergence rate was:

$$
E=\left(E_{1} / E_{2}\right) \times 100 \%
$$

where $E$ is the emergence rate, \%; $E_{1}$ is the number of seedlings; $E_{2}$ is the number of seeds.

At the end of September 2019, the cotton yield of each replicate experimental plot was determined. Based on the stage of cotton boll opening, the cotton was picked three times in each plot, and the boll number and weight and the plant number were recorded each time over a row length of $1 \mathrm{~m}$ on film near the soil moisture monitoring device in each experimental plot. The yield of each treatment was measured three times, and the actual yield of each treatment was obtained by taking the average value, which was converted into the yield of each experimental plot.

\subsection{Statistical Analysis}

Soil temperature, moisture, and salinity dynamics and statistical analyses were performed using EXCEL 2010 (Microsoft Corp., Redmond, Washington, DC, USA) and Origin 9.0 (Origin Lab Corp., Northampton, MA, USA). Spatial distribution of soil water and salinity values were presented using Origin 9.0. Statistical analysis software SPSS 25.0 (IBM, Armonk, NY, USA) was used for analysis of variance (2-way (interaction) ANOVA) and Pearson correlation analysis. Origin 9.0 was used to fit the data for emergence rate or yield with respect to initial salt concentration or winter irrigation rate, respectively.

\section{Results and Analysis}

\subsection{Effects of Different Winter Irrigation Rates on Soil Temperature in Cotton Fields with Different Levels of Salinization}

\subsubsection{Changes in Soil Temperature}

Winter irrigation can stabilize the soil temperature, effectively slowing down the fluctuation range of soil temperature during the stages of soil cooling and warming, with the effect decreasing with increasing soil depth. During the winter, the soil layer $0-40 \mathrm{~cm}$ is a completely frozen zone, with a great fluctuation of soil temperature with time, whereas the soil layer $40-100 \mathrm{~cm}$ is a transitional zone between the completely frozen zone and the unfrozen zone. Based on the variation characteristics of soil temperature with soil depth, the soil layer $0-100 \mathrm{~cm}$ is divided into two layers from top to bottom: the upper layer $(0-40 \mathrm{~cm})$ and the lower layer $(40-100 \mathrm{~cm})$. Compared with the control treatment without winter irrigation (W0), the variation of soil temperature in salinized cotton fields S1, S2, and S3 under the impact of winter irrigation rates W1, W2, and W3 was reduced to different extents. Before winter irrigation and before spring plowing in the following year, that is, from early November to late April, the soil temperature under each treatment showed a decreasing-stable-increasing trend with time. Under the control conditions (W0) of the soils of different salinities, the order of the average temperature of the upper soil layer $(0-40 \mathrm{~cm})$ was $\mathrm{S} 1\left(2.61^{\circ} \mathrm{C}\right)>\mathrm{S} 2\left(2.06^{\circ} \mathrm{C}\right)>\mathrm{S} 3\left(1.82^{\circ} \mathrm{C}\right)$, whereas, under the winter irrigation treatment, the order was $\mathrm{S} 1\left(3.17^{\circ} \mathrm{C}\right)>\mathrm{S} 2\left(3.04^{\circ} \mathrm{C}\right)>\mathrm{S} 3\left(2.74^{\circ} \mathrm{C}\right)$. Under the same winter irrigation rate, the soil temperature in $\mathrm{S} 1, \mathrm{~S} 2$, and $\mathrm{S} 3$ of the salinized cotton fields increased by an average of $21.29 \%, 47.15 \%$, and $51.01 \%$, respectively, compared with the control group without winter irrigation. In soil with the same salinity, the soil temperature under the winter irrigation rates W1, W2, and W3 increased by $35.55 \%, 39.48 \%$, and $44.42 \%$ on average, respectively, compared with the control group without winter irrigation. Under the control treatment of different saline cotton fields without winter irrigation, the order of the average temperature of the lower soil layer $(40-100 \mathrm{~cm})$ was $\mathrm{S} 1\left(4.55^{\circ} \mathrm{C}\right)>\mathrm{S} 2\left(4.47^{\circ} \mathrm{C}\right)>\mathrm{S} 3\left(3.63^{\circ} \mathrm{C}\right)$, whereas, under the winter irrigation treatment, the order was $\mathrm{S} 2\left(5.46^{\circ} \mathrm{C}\right)>\mathrm{S} 1\left(5.33^{\circ} \mathrm{C}\right)>\mathrm{S} 3\left(5.31^{\circ} \mathrm{C}\right)$. At the same winter irrigation rate, the soil temperature in soil salinities S1, S2, and S3 increased by an average of $17.18 \%, 22.03 \%$, and $46.28 \%$, respectively, compared 
with the control group without winter irrigation; at the same soil salinity, the soil temperature under the winter irrigation rates $\mathrm{W} 1, \mathrm{~W} 2$, and $\mathrm{W} 3$ increased by $24.77 \%, 29.27 \%$, and $31.43 \%$ on average, respectively, compared with the control group without winter irrigation.

The average temperature change ratios between the upper $0-40 \mathrm{~cm}$ and the lower $40-100 \mathrm{~cm}$ layers were $39.82 \%$ and $28.49 \%$, respectively (Figure 3). The relative temperature change in the $0-40 \mathrm{~cm}$ soil layer to temperature change and winter irrigation treatment was significantly higher than that of the 40-100 cm soil layer. Under the same winter irrigation rate, the increase in soil average temperature of S1 soil was significantly lower than that in S2 and S3 soils, respectively $(p<0.05)$, but there was no significant difference between S2 and S3 $(p>0.05)$. Under the effects of winter irrigation rates W1, W2, and W3 in soil of the same salinity level, there was a significant difference in average soil temperature $(p<0.05)$. The winter irrigation treatments and the different soil salinities all had the effect of stabilizing the soil temperature. The effects of winter irrigation rate and soil salinity level on soil temperature were significant $(p<0.05)$ (Figure 3). The average soil temperature of each treatment increased with the increasing winter irrigation rate and decreased with the increasing soil salinity level. The increased average soil temperature of each treatment increased with the increase in winter irrigation rate and soil salinization degree. The response of soil temperature to winter irrigation in moderately and severely salinized cotton fields was significantly higher than that in lightly salinized cotton fields $(p<0.05)$ (Figure 3).
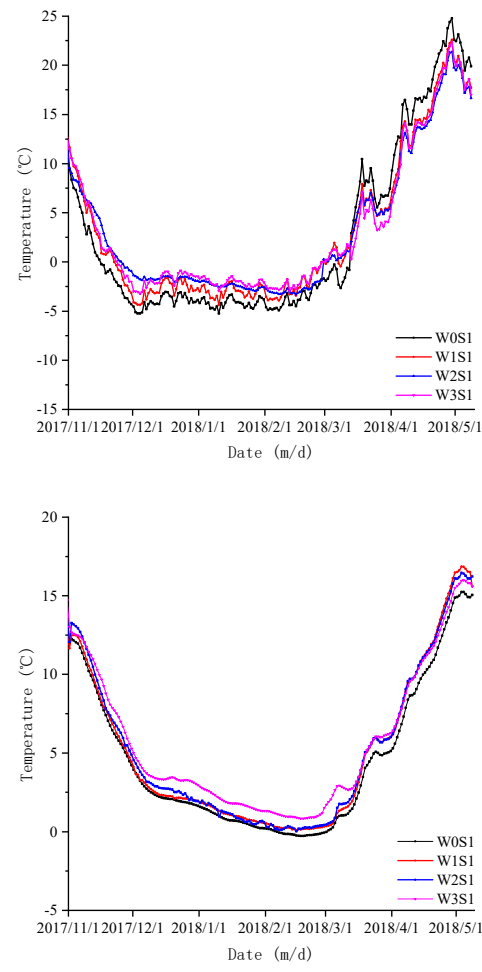

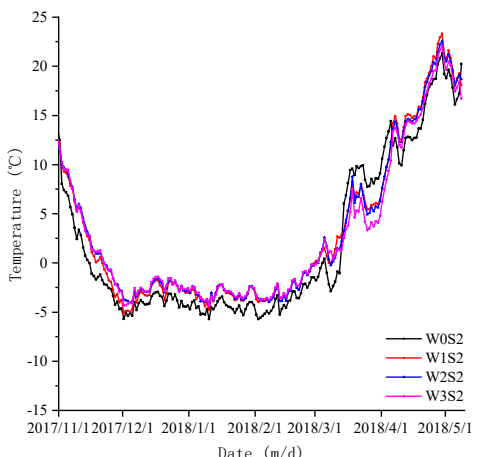

(a)

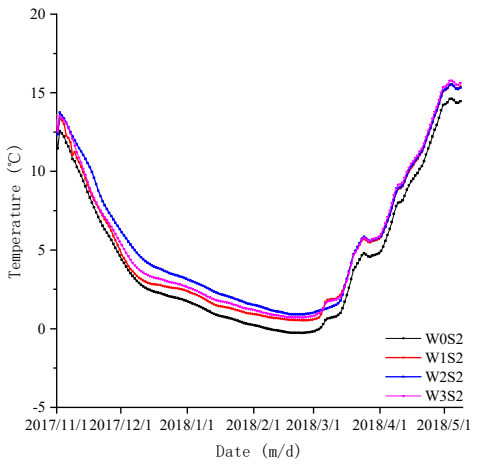

(b)
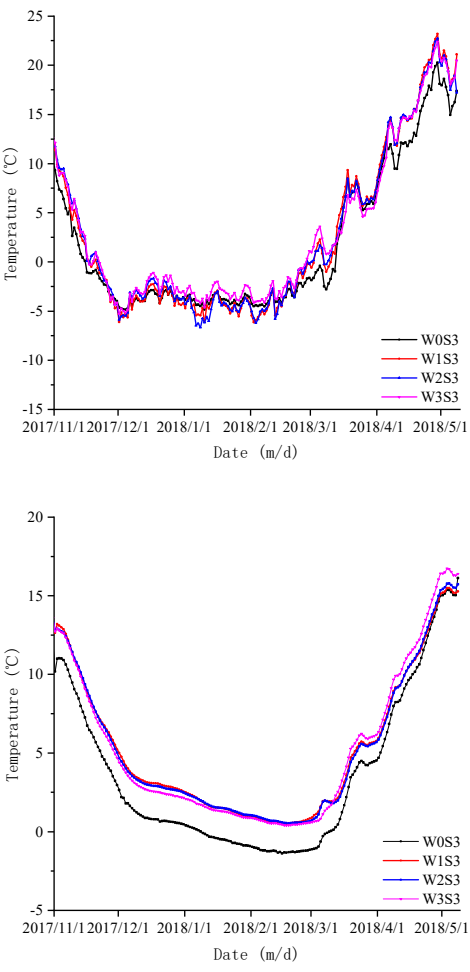

Figure 3. Soil temperature changes during the freezing-thawing period. (a) Soil temperature of the soil layer 0-40 cm; (b) Soil temperature of the soil layer $40-100 \mathrm{~cm}$.

\subsubsection{Changes in Soil Freezing-Thawing Index}

Winter irrigation changes the energy conversion between shallow soil temperature and solar radiation and affects soil freezing and thawing indexes. In this study, the soil freezing-thawing index was calculated based on soil temperature of the 0-40 $\mathrm{cm}$ layer (Figure 4). In the lightly salinized cotton field S1, the difference in soil freezing-thawing index under winter irrigation rates W1, W2, and W3 was significantly different $(p<0.05)$, and the order of the freeze-thaw index absolute value was $\mathrm{W} 1>\mathrm{W} 2>\mathrm{W} 3$. In the salinized cotton field S2, the difference in soil freezing index between soils 
exposed to winter irrigation rates W1, W2, and W3 was not significantly different $(p>0.05)$, although the soil thawing index under winter irrigation rate treatment $W 3$ was significantly lower than that under both W1 and W2 treatments $(p<0.05)$, and the difference in soil thawing index under the winter irrigation rates W1 and W2 was not significant $(p>0.05)$ (Figure 4). In the heavily salinized cotton field S3, the soil freezing index under winter irrigation rate W3 was significantly different from that under the W1 and W2 treatments $(p<0.05)$, but the difference in soil freezing index under the rates $\mathrm{W} 1$ and W2 was not significant $(p>0.05)$, although the differences in soil thawing index values in response to the winter irrigation rates $\mathrm{W} 1, \mathrm{~W} 2$, and W3 were significant $(p<0.05)$, and the order of the thawing index was W1 $>$ W2 $>$ W3. Except that there was no significant difference in the thawing indexes of the S2 and S3 salinized cotton fields under the winter irrigation rate W2 $(p>0.05)$, soil freezing-thawing indexes of the S1, S2, and S3 salinized cotton fields under the same winter irrigation rate were significantly different $(p<0.05)$ (Figure 4$)$.

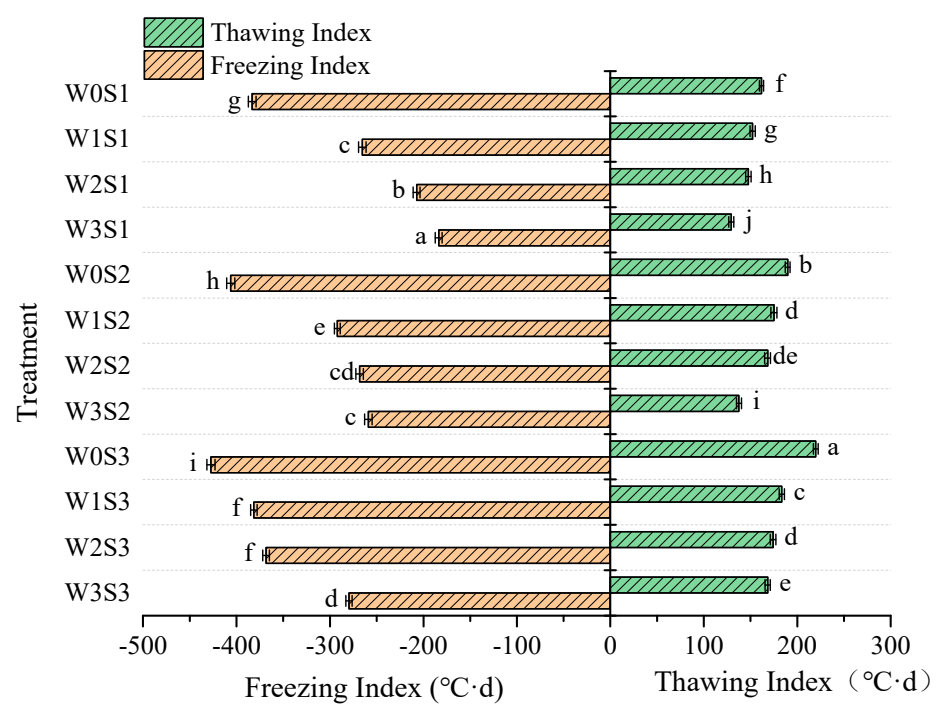

Figure 4. Freezing-thawing index of the $0-40 \mathrm{~cm}$ soil depth during freezing and thawing periods. Each data point represents the mean \pm standard error. Any two samples in the same bar chart with a shared lowercase letter were not significantly different $(p>0.05)$.

The order of the soil freezing-thawing index values for all test groups was S3 > S2 $>$ S1. Under the same winter irrigation rate, the freezing index values in saline cotton fields S1, S2, and S3 were reduced by $42.92 \%, 32.76 \%$, and $19.70 \%$ on average, respectively, compared with those in W0. In the same saline cotton field, the freezing index value under the winter irrigation rates W1, W2, and W3 decreased by an average of $23.18 \%, 31.23 \%, 40.97 \%$, respectively, compared with the treatment without winter irrigation (Figure 4). Under the same winter irrigation rate, the thawing indices in saline cotton fields S1, S2, and S3 were reduced by $11.57 \%, 15.53 \%$, and $20.23 \%$ on average, respectively, compared with those with no winter irrigation. In the same saline cotton field, the thawing index value under the treatments of winter irrigation rates $\mathrm{W} 1$, W2, and $\mathrm{W} 3$ decreased by $10.07 \%, 13.62 \%$, and $23.64 \%$ on average, respectively, compared with the W0 treatment, without winter irrigation. The values of the freezing-thawing index in the $0-40 \mathrm{~cm}$ layer of saline cotton fields S1, S2, and S3 under different irrigation rates were all significantly lower than those under the control treatment $(p<0.05)$ without winter irrigation. Under the same irrigation rate, the freezing-thawing index values all significantly increased as the salinization degree increased $(p<0.05)$, whereas, in the same salinized soil, the freezing-thawing index values all decreased as the winter irrigation rate increased (Figure 4). Based on the research results, winter irrigation significantly reduced the soil freezing-thawing index value, particularly via the freezing index of the mildly saline soil and the thawing index of the severely saline soil $(p<0.05)$ (Figure 4). 


\subsection{Effects of Different Winter Irrigation Rates on Soil Moisture in Soil With Different Salinities}

\subsubsection{Temporal and Spatial Variation of Soil Moisture}

The dynamic changes of soil moisture over time in the soil layer 0-100 $\mathrm{cm}$ under different winter irrigation rates in cotton fields with different salinization levels are shown in Figure 5. The change in soil moisture in the $0-100 \mathrm{~cm}$ soil layer with time was similar in each salinized soil level under different winter irrigation rate treatments. On the 7th day after the end of the winter irrigation, that is, in early November, the winter irrigation water continued to seep downward, and the water content in the $0-100 \mathrm{~cm}$ soil layer increased rapidly, resulting in saturated aquifers at different depths. On the 15th day after the end of winter irrigation, in mid-November, the temperature dropped rapidly, and the soil appeared to freeze. The moisture of the frozen soil layer $0-20 \mathrm{~cm}$ began to move toward the frozen edge, and the moisture of the soil layer $20-100 \mathrm{~cm}$ was basically unchanged. During the freezing period, that is, from mid-November 2018 to early March 2019, the frozen depth increased due to the continuous decrease in temperature. A small amount of unfrozen water in the $0-20 \mathrm{~cm}$ of the original frozen soil layer slowly moved downward, whereas the temperature of the water in the 20-60 cm layer of the newly frozen soil layer continuously and rapidly decreased, and the water in the $60-100 \mathrm{~cm}$ layer of the unfrozen soil layer slowly decreased (Figure 5). During the snow-thawing period, that is, from early March to early April, the temperature rose rapidly, so that the frozen soil layer and the thick snow on the surface thawed in both directions, and the melted water moved up and down at the same time. The water content of the $0-20 \mathrm{~cm}$ layer of the frozen soil was restored to the level of $15 \mathrm{~d}$ after irrigation, and the water content of the 20-100 cm soil layer was restored to the approximate saturation level achieved $7 \mathrm{~d}$ after irrigation (Figure 5). During the initial evaporation period, that is, from early April to mid-April, the temperature continued to rise, and the surface radiation increased, which caused the evaporation from the soil surface layer to be intense. The evaporation of water from the soil layer 0-20 cm decreased, whereas the water in the soil layer 20-100 cm moved slowly downward and the soil water content remained as high as the water content after irrigation (Figure 5).
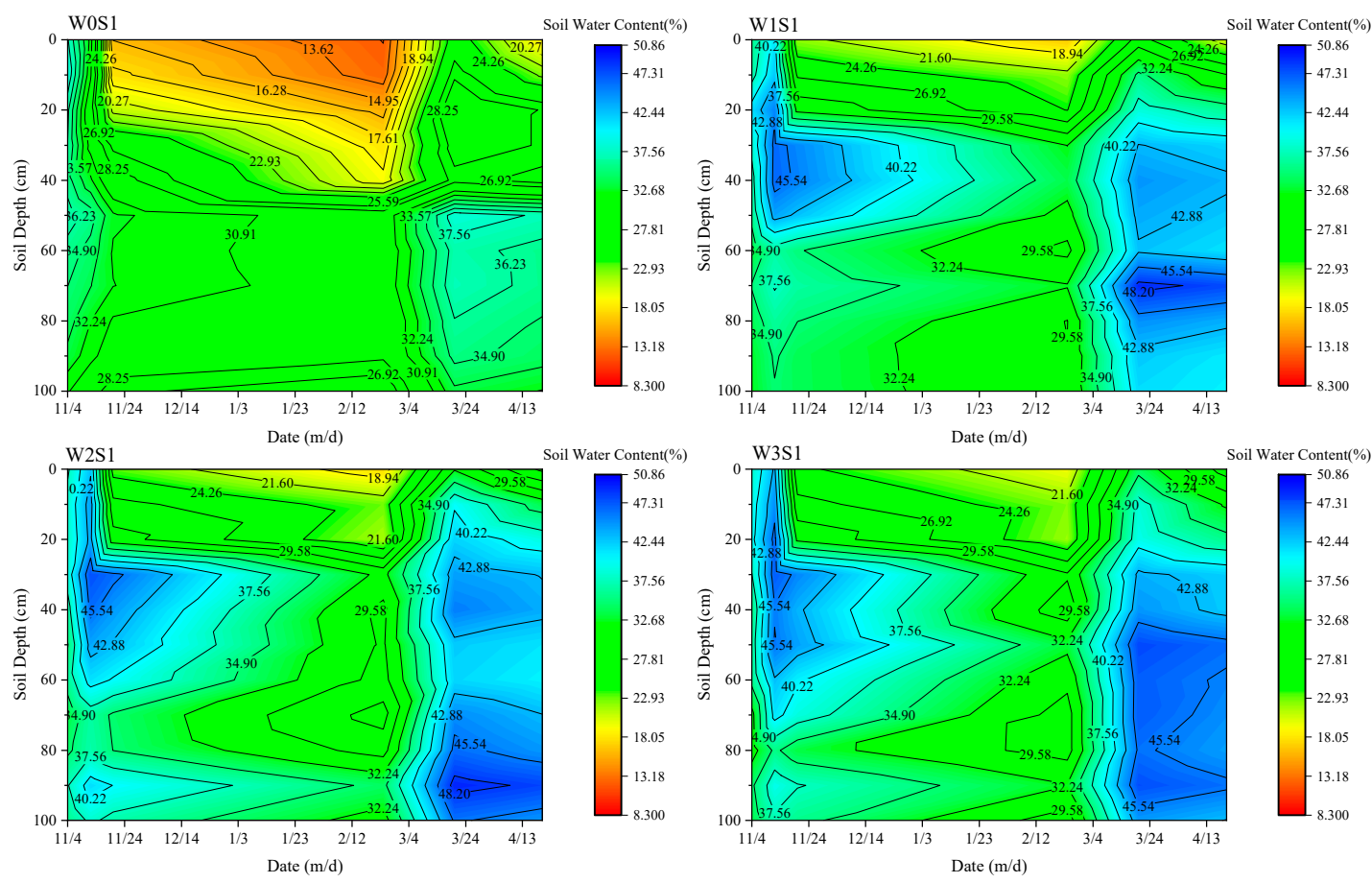

(a)

Figure 5. Cont. 

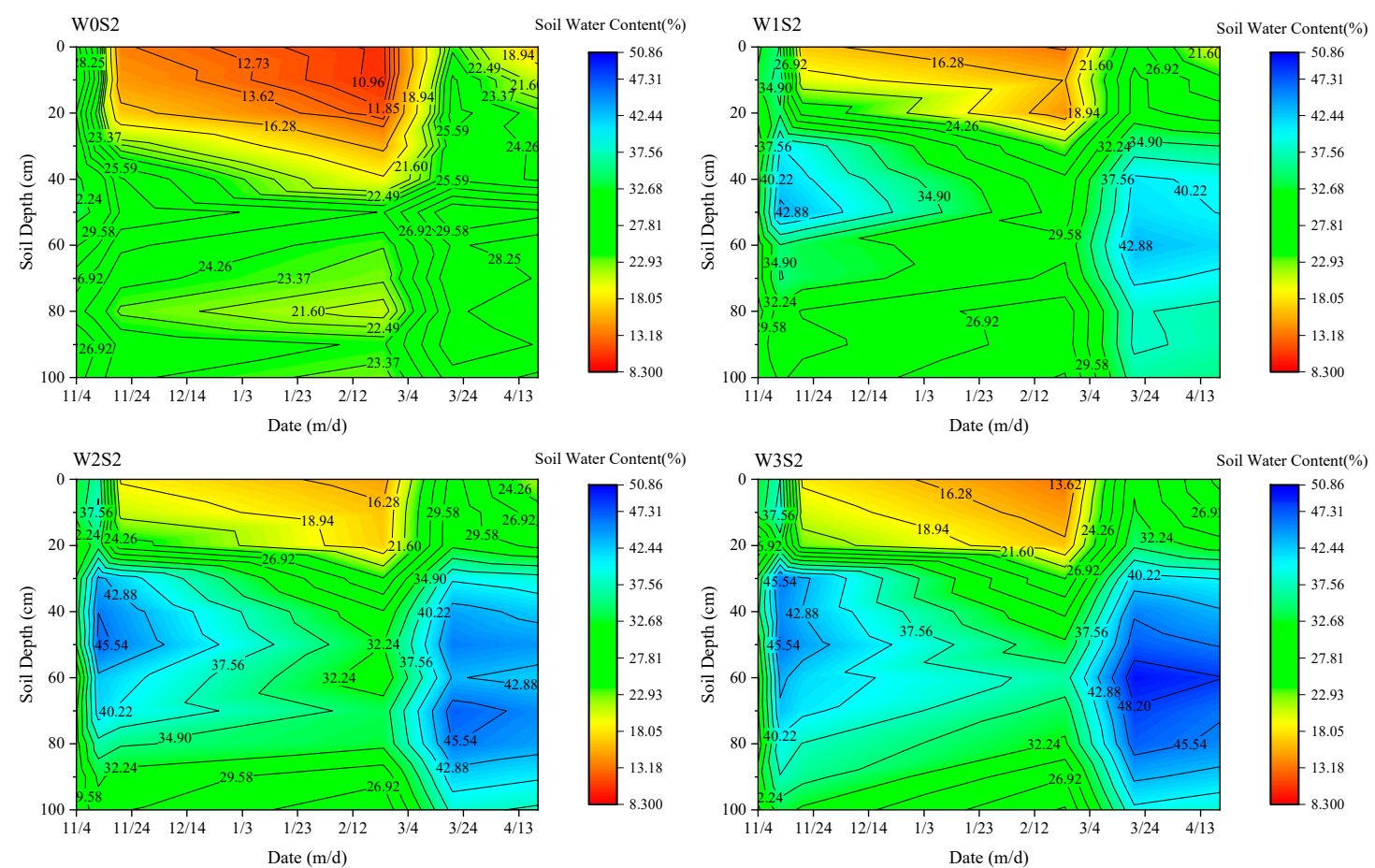

Soil Water Content(\%)

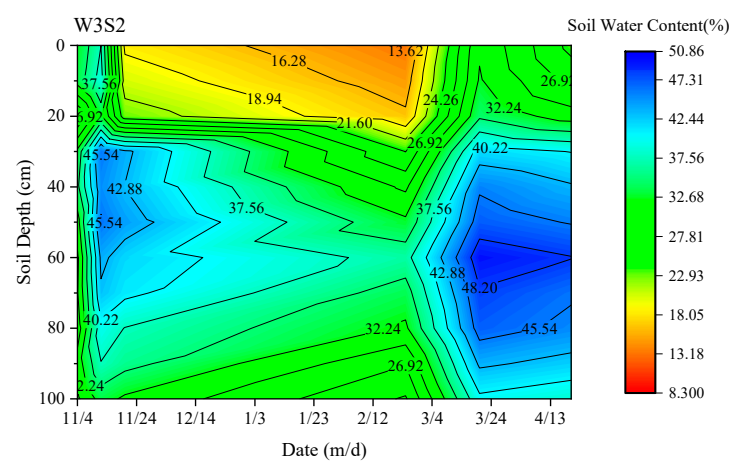

(b)
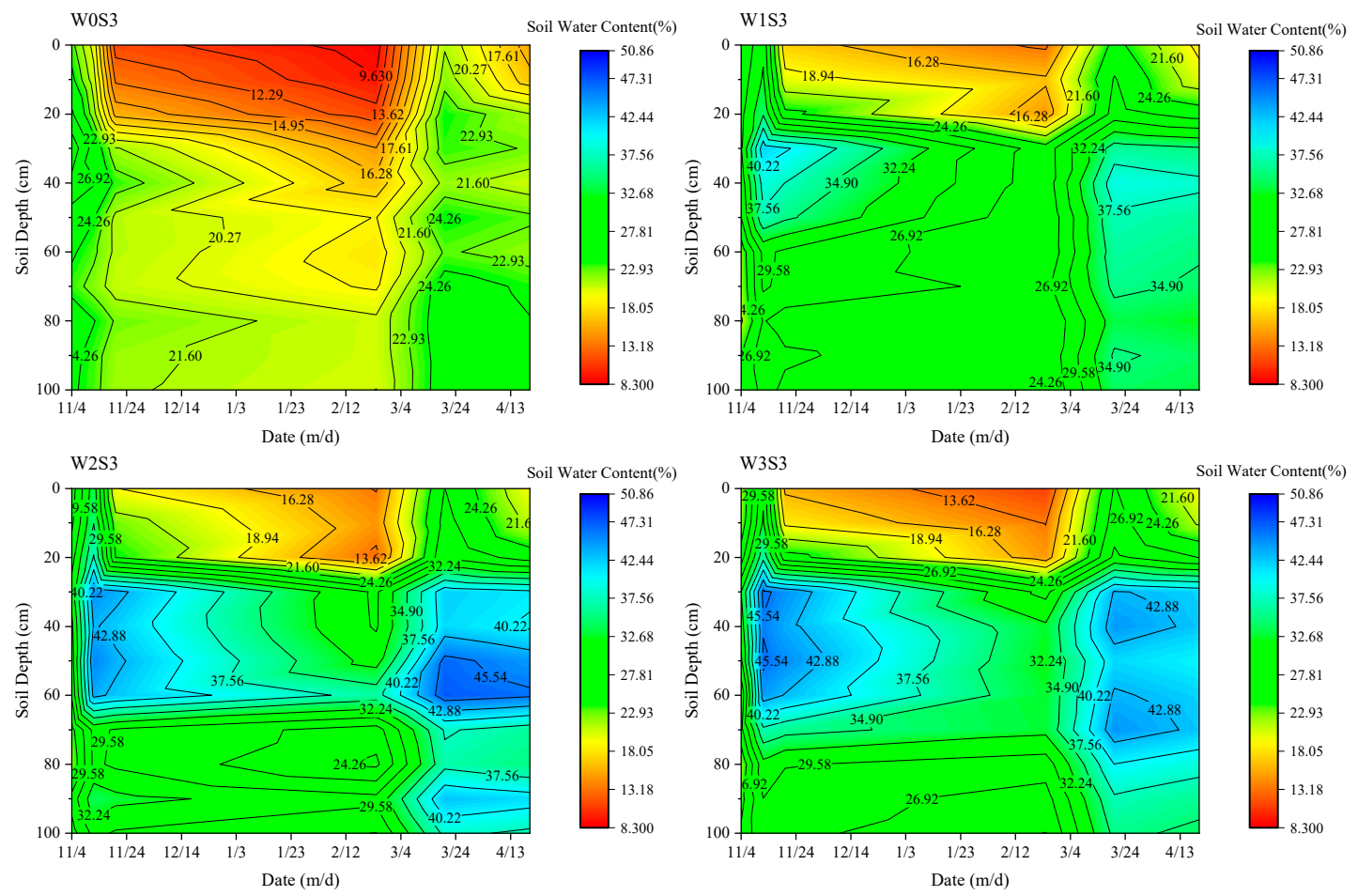

Soil Water Content(\%)
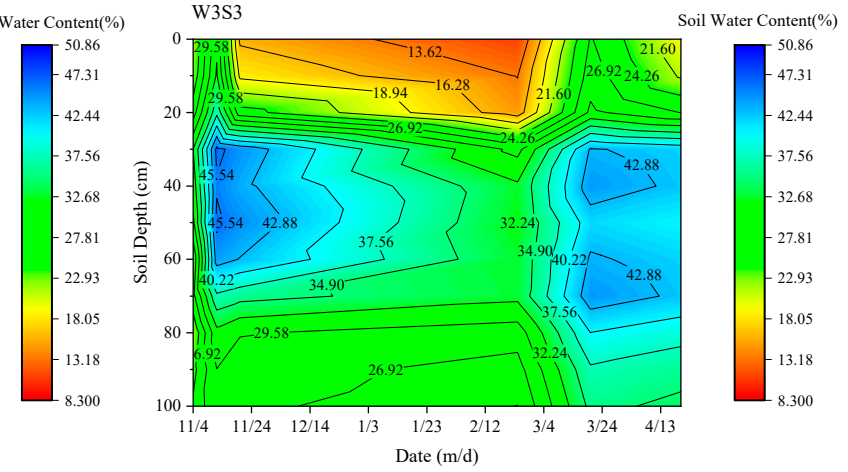

(c)

Figure 5. Temporal and spatial variations of soil moisture in cotton fields with different degrees of salinization. (a) Mildly salinized cotton field S1; (b) Moderately salinized cotton field S2; (c) Severely salinized cotton field S3.

For the saline cotton fields S1, S2, and S3, there were significant differences in soil water distribution between the control treatment without winter irrigation (W0) and the winter irrigation treatments (W1, W2 and W3) $(p<0.05)$. A saturated aquifer appeared in the $0-100 \mathrm{~cm}$ soil layer of the saline cotton fields on the 7th day after winter irrigation and the initial evaporation period. In the saline 
cotton fields S1, S2, and S3, the depth and duration of the saturated aquifer in the soil on the 7th after irrigation and the initial evaporation period were different under the different winter irrigation rates W1, W2, and W3 (Figure 5). There was no significant difference in S1 under the W1, W2, and W3 treatments $(p>0.05)$, and the duration and depth of the moisture-saturated soil layer were good. The soil moisture in treatment W1 was significantly lower than that under W2 and W3 treatments $(p<0.05)$ in S2, but no significant differences were observed between treatments W2 and W3 $(p>0.05)$, and the depth and duration of the saturated aquifer under W1 treatment were lower than those in treatments W2 and W3. There were significant differences in S3 under the treatments of W1, W2, and W3 $(p<0.05)$, and no saturated aquifer appeared in the W1 treatment, with the depth and duration of the saturated aquifer under the W2 treatment being better than that under the W3 treatment (Figure 5).

\subsubsection{Changes in Soil Water Content}

The changes in soil moisture content after freezing-thawing in the winter-irrigated cotton fields are shown in Table 4. Before winter irrigation, the water content of the $0-40 \mathrm{~cm}$ and $0-100 \mathrm{~cm}$ soil layers was significantly related to only the initial salt content of the soil $(p<0.05)$, and the soil water content was in the order S1 > S2 > S3. Before the spring tillage of the saline cotton fields S1, S2, and S3, there was a significant difference between the soil water content in the winter irrigation control (W0) and the winter irrigation treatments $(p<0.05)$. The water content in the soil layers $0-40 \mathrm{~cm}$ and $0-100 \mathrm{~cm}$ in the saline cotton fields without winter irrigation decreased by an average of $30.23 \%$ and $15.28 \%$, respectively, compared with that before irrigation. The soil water content decreased with an increase in degree of salinization, and the water content in the saline cotton fields decreased after freezing and thawing. In the plots without winter irrigation, the water content in the $0-40 \mathrm{~cm}$ and $0-100 \mathrm{~cm}$ soil layers decreased by $30.23 \%$ and $15.28 \%$ on average, respectively, compared with that before irrigation, and the percentage reduction in water content decreased as the degree of salinization increased (Table 4). After the end of the freezing-thawing period, the water content in the salinized cotton plots decreased and the amount of water lost in the upper 0-40 cm soil layer was greater. The water content of different salinized cotton fields under winter irrigation treatments was higher than that of the control treatment without winter irrigation. The water contents of the $0-40 \mathrm{~cm}$ and $0-100 \mathrm{~cm}$ soil layers under winter irrigation treatment were significantly correlated with the winter irrigation rate and the initial salt concentration of the soil $(p<0.05)$. Under the same winter irrigation rate, the water content of the $0-40 \mathrm{~cm}$ and $0-100 \mathrm{~cm}$ soil layers in the S1, S2, and S3 soils was significantly different $(p<0.05)$. The average increase in soil water content in the $0-40 \mathrm{~cm}$ and $0-100 \mathrm{~cm}$ soil layers of the soils with different degrees of salinization under winter irrigation was S3 $(5.32 \%)>\mathrm{S} 2(-0.97 \%)$ $>$ S1 $(-6.27 \%)$ and S3 $(29.38 \%)>$ S2 $(22.68 \%)>$ S1 $(11.31 \%)$, respectively (Table 4$)$.

Before spring plowing, the soil moisture content in the $0-40 \mathrm{~cm}$ soil layer in mildly, moderately, and severely saline cotton fields decreased slightly, whereas the soil moisture content of the $0-100$ $\mathrm{cm}$ soil layer in each of the three salinized soils increased significantly, with the water content of the severely saline cotton fields increasing the most. Under the same saline cotton field, the water content in the $0-40 \mathrm{~cm}$ soil layer was significantly different under the different winter irrigation rates $(p<0.05)$, whereas the degree of water content in the 0-100 cm soil layer was different (Table 4). For field S1, the water content of the $0-100 \mathrm{~cm}$ soil layer under winter irrigation rate $\mathrm{W} 1$ was significantly lower than that under W2 and W3 rates, with no significant differences in water content of the $0-100 \mathrm{~cm}$ soil layer under $\mathrm{W} 2$ and $\mathrm{W} 3$ rates $(p>0.05)$. The decrease in water content in the soil layer $0-40 \mathrm{~cm}$ was shown as $\mathrm{W} 1>\mathrm{W} 3>\mathrm{W} 2$, and the increase in water content in the soil layer $0-100 \mathrm{~cm}$ was in the order $W 3>W 2>W 1$. For saline cotton field S2, the water content of the $0-100 \mathrm{~cm}$ soil layer under the treatment of winter irrigation rates W1, W2, and W3 was significantly different $(p<0.05)$. The decrease in water content of the soil layer $0-40 \mathrm{~cm}$ was in the order $\mathrm{W} 1>\mathrm{W} 2>\mathrm{W} 3$ (with the water content of the soil layer $0-40 \mathrm{~cm}$ increasing particularly in the W3S2 treatment), whereas the increase in water content in the soil layer 0-100 cm was in the order W3 > W2 > W1. For the highly saline cotton field S3, the water content of the $0-100 \mathrm{~cm}$ soil layer under winter irrigation rate W1 was significantly different 
from that under W2 or W3, with no significant differences in water content in the $0-100 \mathrm{~cm}$ soil layer between W2 and W3 $(p>0.05)$ (Table 4). The increase in water content in the soil layers $0-40 \mathrm{~cm}$ and $0-100 \mathrm{~cm}$ were in the order W3 $>$ W2 $>$ W1 (with the water content of the soil layer $0-40 \mathrm{~cm}$ decreasing particularly in the W1S3 treatment) (Table 4).

Table 4. Soil water content in each treatment.

\begin{tabular}{|c|c|c|c|c|c|c|c|}
\hline \multicolumn{2}{|c|}{ Treatment } & \multicolumn{2}{|c|}{$\begin{array}{c}\text { M1 } \\
\text { Soil Water Storage } \\
\text { before Winter } \\
\text { Irrigation }(\mathrm{mm})\end{array}$} & \multicolumn{2}{|c|}{$\begin{array}{c}\text { M2 } \\
\text { Soil Water Storage } \\
\text { before Spring } \\
\text { Plowing }(\mathbf{m m})\end{array}$} & \multicolumn{2}{|c|}{$\begin{array}{c}(\mathrm{M} 2-\mathrm{M} 1) / \mathrm{M} 1 \\
\text { Changes in Soil Water } \\
\text { Content }(\%)\end{array}$} \\
\hline $\begin{array}{c}\text { Initial Salt } \\
\text { Concentration/ } \\
\left(\mathbf{g} \cdot \mathbf{k g}^{-1}\right)\end{array}$ & $\begin{array}{c}\text { Winter } \\
\text { Irrigation } \\
\text { Rate } /\left(\mathbf{m}^{3} \cdot \mathbf{h m}^{-2}\right)\end{array}$ & $0-40 \mathrm{~cm}$ & $0-100 \mathrm{~cm}$ & $0-40 \mathrm{~cm}$ & $0-100 \mathrm{~cm}$ & $0-40 \mathrm{~cm}$ & $0-100 \mathrm{~cm}$ \\
\hline \multirow{4}{*}{ S1 } & W0 & $147.59 \mathrm{~b}$ & $354.98 \mathrm{~b}$ & $98.79 \mathrm{i}$ & $303.03 \mathrm{~g}$ & $-33.07 \%$ & $-14.63 \%$ \\
\hline & W1 & $150.71 a$ & $355.64 \mathrm{~b}$ & $136.76 \mathrm{c}$ & $388.03 \mathrm{~b}$ & $-9.26 \%$ & $+9.11 \%$ \\
\hline & W2 & $150.91 a$ & $363.86 a$ & $146.02 \mathrm{a}$ & $403.26 a$ & $-3.24 \%$ & $+10.83 \%$ \\
\hline & W3 & $151.36 a$ & $355.76 b$ & $141.83 \mathrm{ab}$ & $405.57 \mathrm{a}$ & $-6.30 \%$ & $+14.00 \%$ \\
\hline \multirow{4}{*}{ S2 } & W0 & $124.28 \mathrm{de}$ & 298.03de & 87.67j & $252.03 \mathrm{~h}$ & $-29.46 \%$ & $-15.43 \%$ \\
\hline & W1 & $123.62 \mathrm{e}$ & $294.02 \mathrm{e}$ & $117.72 \mathrm{~g}$ & $343.14 \mathrm{e}$ & $-4.76 \%$ & $+16.71 \%$ \\
\hline & W2 & $128.53 c$ & $302.09 \mathrm{~cd}$ & $125.41 \mathrm{e}$ & $372.3 c$ & $-2.43 \%$ & $+23.24 \%$ \\
\hline & W3 & $125.59 \mathrm{~d}$ & $304.06 c$ & $130.97 \mathrm{~cd}$ & $389.46 \mathrm{~b}$ & $+4.29 \%$ & $+28.08 \%$ \\
\hline \multirow{4}{*}{ S3 } & W0 & $108.54 \mathrm{~g}$ & $258.82 \mathrm{~g}$ & 77.96k & $217.97 \mathrm{i}$ & $-28.17 \%$ & $-15.78 \%$ \\
\hline & W1 & $113.14 \mathrm{f}$ & $257.34 \mathrm{~g}$ & 109.77h & $311.62 \mathrm{f}$ & $-2.98 \%$ & $+21.09 \%$ \\
\hline & W2 & $112.04 \mathrm{f}$ & $268.27 \mathrm{f}$ & $117.29 \mathrm{~g}$ & $351.44 \mathrm{~d}$ & $+4.69 \%$ & $+31.00 \%$ \\
\hline & W3 & $106.16 \mathrm{~h}$ & $257.14 \mathrm{~g}$ & $121.29 \mathrm{f}$ & $349.83 d$ & $+14.26 \%$ & $+36.05 \%$ \\
\hline \multicolumn{2}{|c|}{ W } & ns & ns & $* *$ & $* *$ & $* *$ & $* *$ \\
\hline \multicolumn{2}{|c|}{ S } & $*$ & $*$ & * & $* *$ & * & ** \\
\hline \multicolumn{2}{|c|}{$\mathrm{W} \times \mathrm{S}$} & ns & ns & $* *$ & ** & $* *$ & ** \\
\hline
\end{tabular}

Note: W0, W1, W2, and W3 represent the winter irrigation quota of $0,3000,3600$, and $4200 \mathrm{~m}^{3} \cdot \mathrm{hm}^{-2}$, respectively, whereas S1, S2, and S3 represent the initial salt concentrations of $6.20,10.17$, and $12.23 \mathrm{~g}^{\circ} \mathrm{kg}^{-1}$, respectively. Shared lowercase letters within a column in the table indicate no significant difference between treatments $(p>0.05)$, ** indicates extremely significant correlation of indicators $(p<0.01),{ }^{*}$ indicates significant correlation of indicators $(p<0.05)$, the same as below.

The average increases in water content in the $0-40 \mathrm{~cm}$ and $0-100 \mathrm{~cm}$ soil layers of the same saline cotton fields under different winter irrigation rates were in the order W3 $(4.08 \%)>$ W2 $(-0.33 \%)>$ W1 $(-5.66 \%)$ and W3 (26.04\%) > W2 (21.69\%) > W1 (15.63\%), respectively. Before spring plowing, the changes in soil moisture content in the same salinized cotton field under different winter irrigation rates were varied. The water content in the $0-40 \mathrm{~cm}$ soil layer under treatments $\mathrm{W} 1$ and $\mathrm{W} 2$ decreased compared with that before irrigation (except for W2S3), whereas the water content in the $0-40 \mathrm{~cm}$ soil layer under treatment W3 increased, compared with that before irrigation (except for W3S1). On the other hand, the soil water content in the $0-100 \mathrm{~cm}$ soil layer under treatments W1, W2, and W3 were all significantly increased $(p<0.05)$, compared with that before irrigation. The effects on water conservation and soil moisture increase under the higher winter irrigation rates were more marked.

\subsection{Effects of Winter Irrigation Rate on Soil Salinity in Fields with Different Salinity Levels}

\subsubsection{Temporal and Spatial Variation of Soil Salinity}

The dynamic changes of soil salinity with time over the $0-100 \mathrm{~cm}$ soil depth under different winter irrigation rates in cotton fields with different salinities are shown in Figure 6. The change in soil salinity in the $0-100 \mathrm{~cm}$ soil layer over time was similar $(p>0.05)$ in each salinized cotton field under different winter irrigation rates. On the 7th day after the end of the winter irrigation, the salt concentration in the soil layer $0-100 \mathrm{~cm}$, along with the movement of the winter irrigation water, resulted in convection and dispersion, and the average salt content in the S1, S2, and S3 salinized cotton fields decreased to 2.54, 4.40 and $6.67 \mathrm{~g} \cdot \mathrm{kg}^{-1}$, respectively (Figure 6). On the 15th day after the end of winter irrigation, the rapid drop in temperature caused the soil to freeze. Under the double action of freezing and evaporation, 
the salt concentration in the $0-20 \mathrm{~cm}$ layer of the frozen soil layer increased slightly, with some salt moving to the frozen edge and accumulating, whereas the salt concentration in the $20-100 \mathrm{~cm}$ soil layer remained basically unchanged. The average salt concentration of soil layer $0-100 \mathrm{~cm}$ in S1, S2, and S3 soils increased to $2.85,5.03$, and $7.63 \mathrm{~g} \cdot \mathrm{kg}^{-1}$, respectively. During the freezing period, the continuous decrease in temperature led to a deepening of the soil freezing depth, and the slow migration and diffusion of salt under the action of soil water potential, temperature potential, and gravity potential. The salt concentration in the $0-20 \mathrm{~cm}$ zone of the original frozen soil layer and the $20-60 \mathrm{~cm}$ zone of the new frozen soil layer decreased, and the salt in the frozen area gradually moved through the freezing front to the unfrozen area after separating out partly. For the salinized cotton fields S1, S2, and S3, the average salt concentration in the frozen soil layer $0-60 \mathrm{~cm}$ decreased to $1.71,3.14$, and $5.28 \mathrm{~g} \cdot \mathrm{kg}^{-1}$, respectively, and the average salt concentration in the unfrozen soil layer 60-100 cm increased to 3.59 , 6.57 , and $9.03 \mathrm{~g} \cdot \mathrm{kg}^{-1}$, respectively. During the snow thawing period, the soil salts migrated downward with the water. In the salinized cotton fields S1, S2, and S3, the average salt concentration in the frozen 0-60 cm soil layer was $2.04,3.61$, and $5.09 \mathrm{~g} \cdot \mathrm{kg}^{-1}$, respectively, and the average salt concentration in the unfrozen $60-100 \mathrm{~cm}$ soil layer decreased to $2.37,4.48$, and $8.00 \mathrm{~g} \cdot \mathrm{kg}^{-1}$, respectively. During the initial evaporation period, the intense evaporation from the soil surface caused the salt to move up through the soil, causing the salt to accumulate in the $0-20 \mathrm{~cm}$ soil layer. The average salt concentration in the soil layer 0-100 cm in soils S1, S2, and S3 increased to $2.72,4.84$, and $7.08 \mathrm{~g} \cdot \mathrm{kg}^{-1}$, respectively, with soil salt concentration being was similar to that on the 7 th day after winter irrigation.
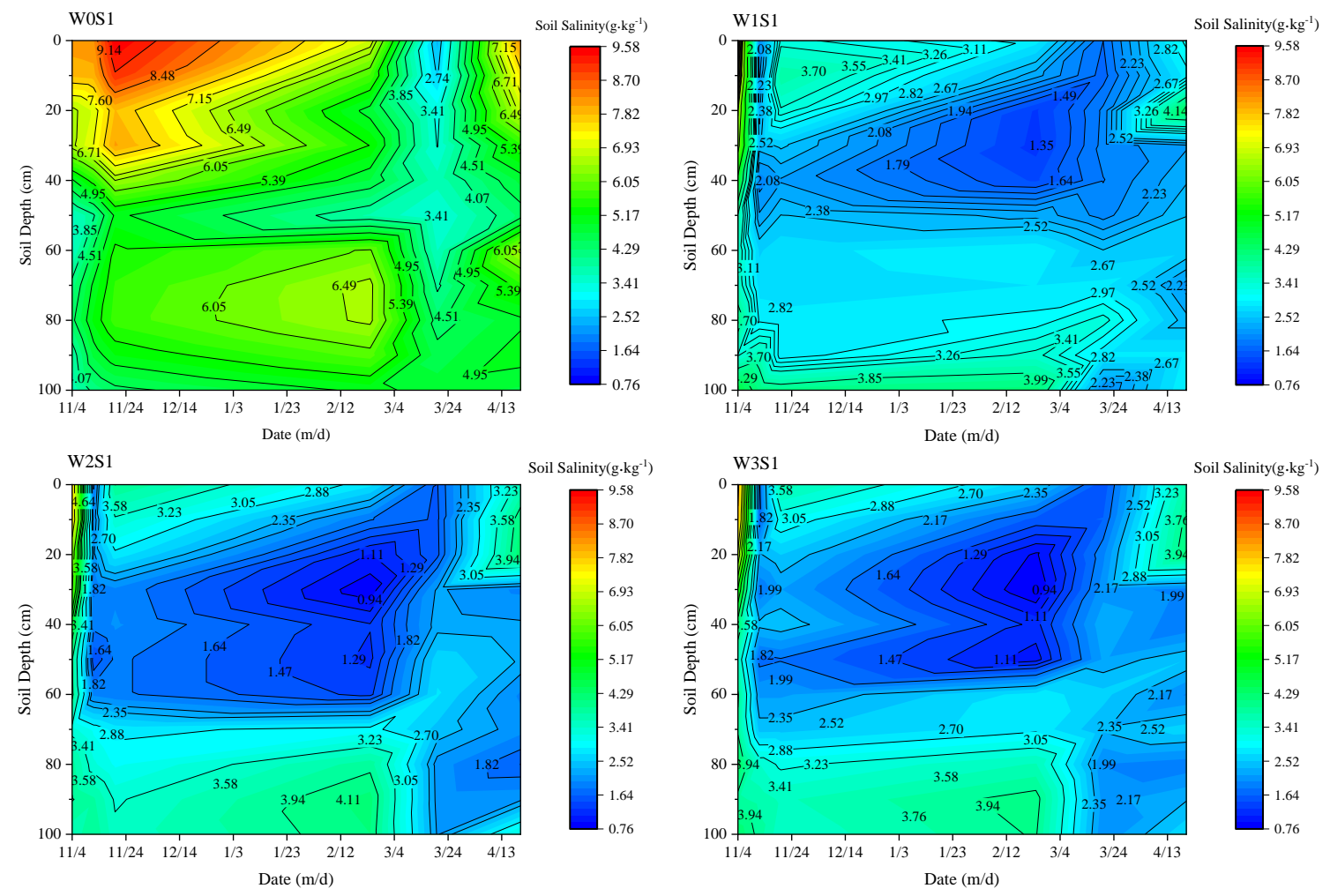

(a)

Figure 6. Cont. 

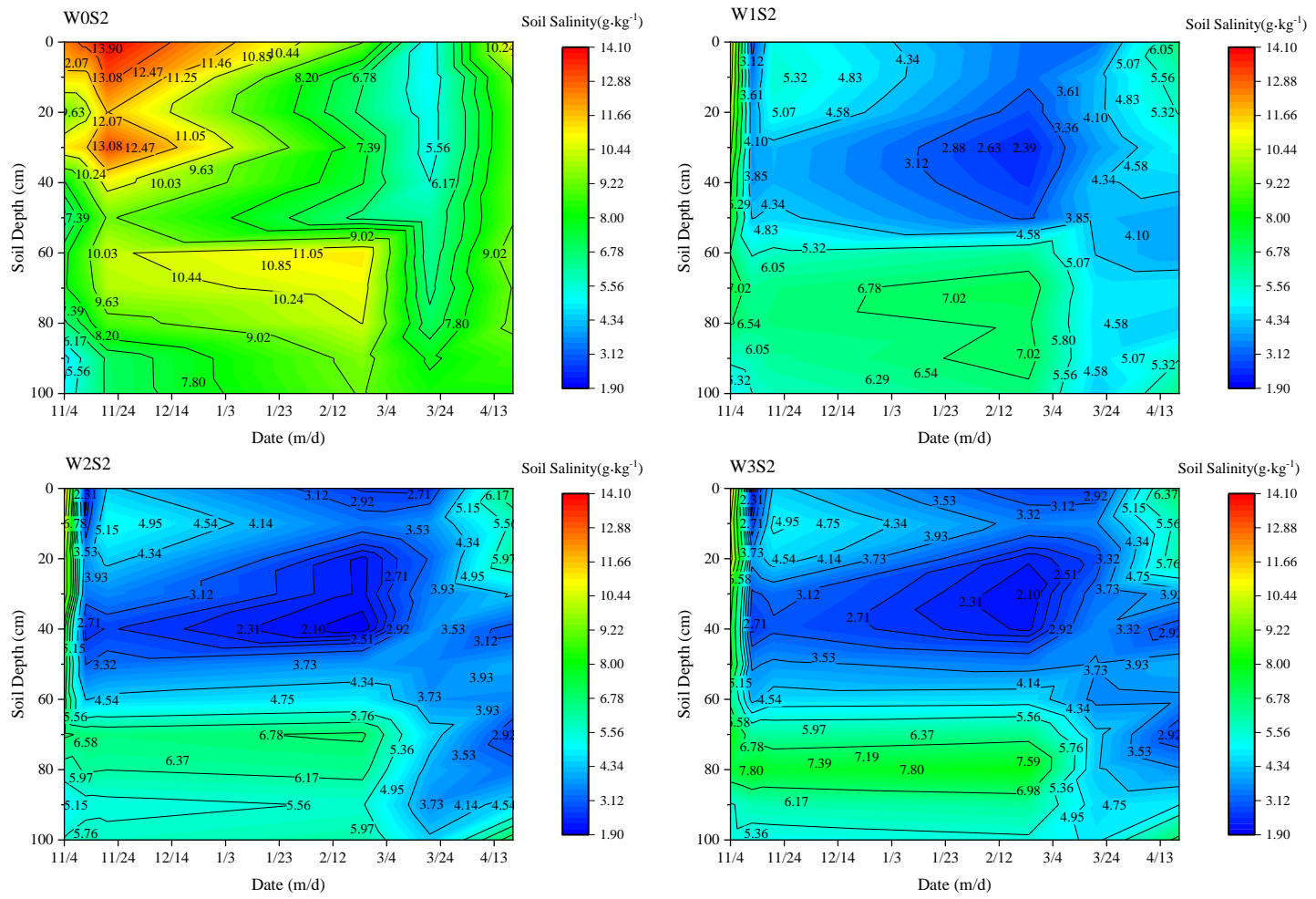

(b)
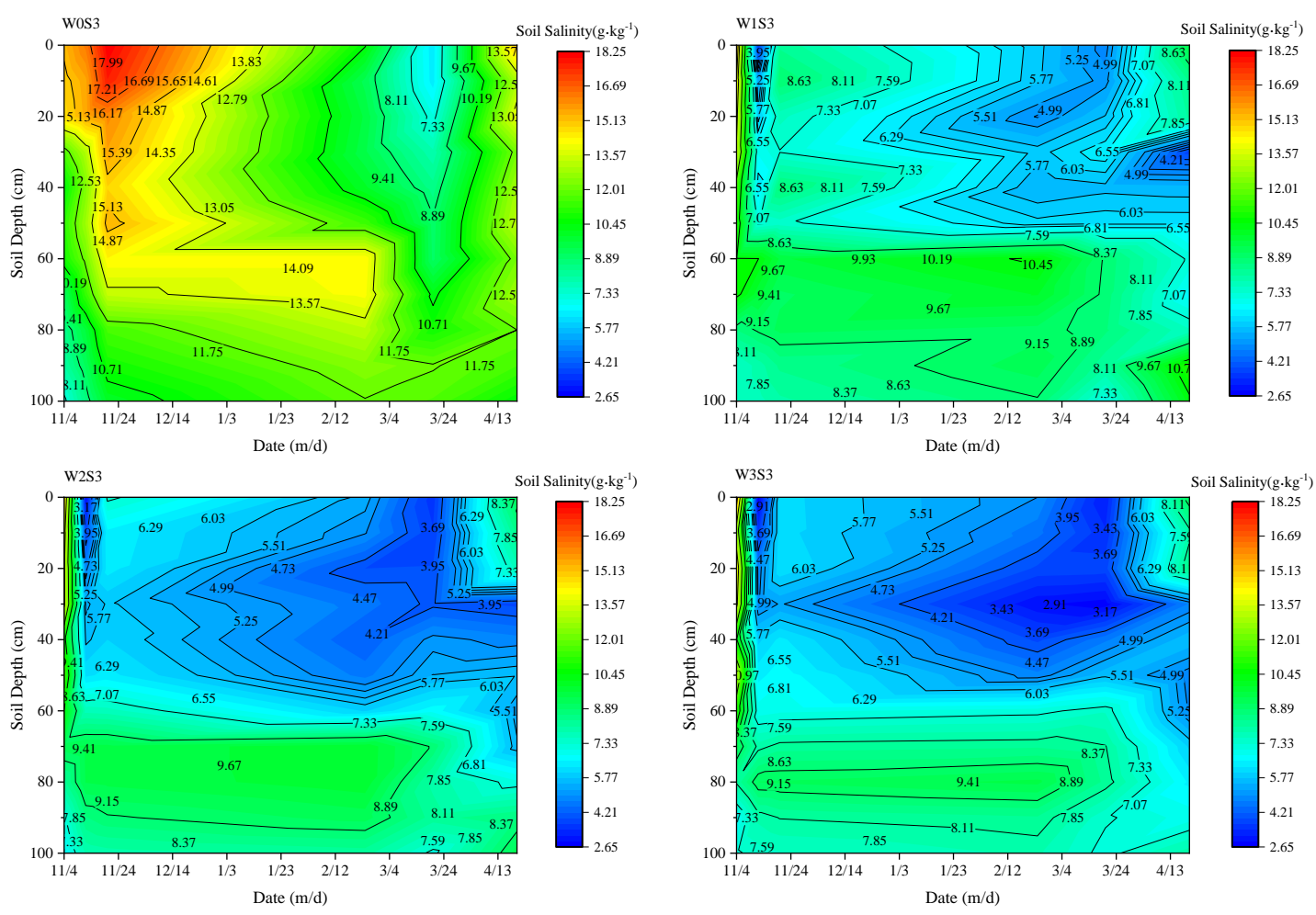

(c)

Figure 6. Temporal and spatial variations of soil salinity in differently salinized cotton fields. (a) Mildly salinized cotton field S1; (b) Moderately salinized cotton field S2; (c) Severely salinized cotton field S3. 
For saline fields S1, S2, and S3, there were significant differences in soil salinity distribution between the control treatment without winter irrigation (W0) and the winter irrigation treatment (W1, W2, and W3) $(p<0.05)$. Winter irrigation could leach soil salt to the deep soil layer, but the depth of desalination and the degree of salt reduction were different for each treatment. Under the same salinized cotton field, the winter irrigation rate (W1) treatment resulted in a soil salt concentration that was significantly higher than those under the W2 and W3 treatments $(p<0.05)$, but there were no significant differences between the W2 and W3 treatment $(p>0.05)$. The amount of soil salt leaching and desalination under the W2 and W3 treatments was significantly greater than that of the W1 treatment, which could effectively inhibit the accumulation of soil salt in the surface layer at the initial evaporation stage.

\subsubsection{Changes in Total Soil Salt Content}

The changes in total soil salt content after freezing in winter-irrigated cotton fields are shown in Table 5. Before winter irrigation, the total soil salt content in the $0-40 \mathrm{~cm}$ and $0-100 \mathrm{~cm}$ soil layers of the cotton fields was significantly related to only the initial salt content of the soil $(p<0.05)$ (Table 6$)$, and the total soil salt contents were in the order S3 $>$ S2 $>$ S1. Before spring tillage, for saline cotton fields S1, S2, and S3, there was a significant difference between the total soil salt content in the control plots (W0) and the plots subjected to winter irrigation treatment $(p<0.05)$. The total soil salt content in the $0-40 \mathrm{~cm}$ and $0-100 \mathrm{~cm}$ soil layers in the saline cotton fields without winter irrigation changed by an average of $-4.33 \%$ and $15.51 \%$, respectively, compared with the values before irrigation. After the end of freezing-thawing, the soil layer $0-40 \mathrm{~cm}$ of salinized cotton fields had desalted slightly but not significantly, and the soil layer 0-100 cm had desalted significantly, and the soil salt content was mainly concentrated in the 40-100 cm soil layer (Table 5). Salinized cotton fields were desalted by winter irrigation and the total soil salt content of the $0-40$ and $0-100 \mathrm{~cm}$ soil layers under winter irrigation treatment was significantly correlated with the winter irrigation rate and the initial salt concentration of the soil $(p<0.05)$ (Table 6). Under the same winter irrigation rate, the total soil salt contents in the $0-40$ and $0-100 \mathrm{~cm}$ layers in S1, S2, and S3 soil of saline cotton field were significantly different $(p<0.05)$. The desalination rate of the $0-40$ and $0-100 \mathrm{~cm}$ soil layers under winter irrigation rate $\mathrm{W} 1$ was in the order S1 $>\mathrm{S} 3>\mathrm{S} 2$ and S1 $>\mathrm{S} 2>\mathrm{S} 3$, respectively; the desalination rate of 0-40 and 0-100 cm soil layers under winter irrigation rate W2 was S3 > S1 > S2 and S1 > S2 > S3, respectively, whereas the order of the desalination rate of both the $0-40$ and $0-100 \mathrm{~cm}$ soil layers under winter irrigation rate $\mathrm{W} 3$ was $\mathrm{S} 1>\mathrm{S} 2>\mathrm{S} 3$. The average desalination rate in $0-40$ and $0-100 \mathrm{~cm}$ soil layers in the different saline cotton fields under winter irrigation was S1 $(51.77 \%)>\mathrm{S} 3(50.56 \%)>\mathrm{S} 2(48.81 \%)$ and S1 $(45.17 \%)>$ S2 $(40.06 \%)>$ S3 $(36.69 \%)$, respectively. In summary, cotton fields with different degrees of salinization exhibited different levels of salt reduction under the same winter irrigation rate, with lightly salted cotton fields (S1) showing greater salt leaching effects. In the same saline cotton field, the total soil salt content in the $0-40$ and $0-100 \mathrm{~cm}$ soil layers differed significantly between different winter irrigation rates. 
Table 5. Soil salt content in each treatment.

\begin{tabular}{|c|c|c|c|c|c|c|c|}
\hline \multicolumn{2}{|c|}{ Treatment } & \multicolumn{2}{|c|}{$\begin{array}{c}\text { C1 } \\
\text { Total Soil Salt } \\
\text { Content before Winter } \\
\text { Irrigation/(g) }\end{array}$} & \multicolumn{2}{|c|}{$\begin{array}{c}\mathrm{C} 2 \\
\text { Total Soil Salt } \\
\text { Content before Spring } \\
\text { Plowing/(g) }\end{array}$} & \multicolumn{2}{|c|}{$\begin{array}{c}(\mathrm{C} 2-\mathrm{C} 1) / \mathrm{C} 1 \\
\text { Relative Changes in } \\
\text { Total Soil Salt/(\%) }\end{array}$} \\
\hline $\begin{array}{c}\text { Initial Salt } \\
\text { Concentration/ } \\
\left(\mathrm{g} \cdot \mathrm{kg}^{-1}\right)\end{array}$ & $\begin{array}{c}\text { Winter } \\
\text { Irrigation } \\
\text { Rate } /\left(\mathrm{m}^{3} \cdot \mathrm{hm}^{-2}\right)\end{array}$ & $0-40 \mathrm{~cm}$ & $0-100 \mathrm{~cm}$ & $0-40 \mathrm{~cm}$ & $0-100 \mathrm{~cm}$ & $0-40 \mathrm{~cm}$ & $0-100 \mathrm{~cm}$ \\
\hline \multirow{4}{*}{ S1 } & W0 & $3836.97 f$ & $7356.13 \mathrm{e}$ & $3634.42 \mathrm{e}$ & $8326.92 \mathrm{f}$ & $-5.28 \%$ & $+13.20 \%$ \\
\hline & W1 & $3779.06 \mathrm{fg}$ & 7251.77e & $1755.68 \mathrm{~h}$ & $4105.88 \mathrm{i}$ & $-53.54 \%$ & $-43.38 \%$ \\
\hline & W2 & $3707.95 \mathrm{fg}$ & $7131.53 \mathrm{e}$ & $1847.95 \mathrm{~h}$ & $3868.47 \mathrm{i}$ & $-50.16 \%$ & $-45.76 \%$ \\
\hline & W3 & $3642.33 \mathrm{~g}$ & $7226.10 \mathrm{e}$ & $1762.48 \mathrm{~h}$ & $3875.14 i$ & $-51.61 \%$ & $-46.37 \%$ \\
\hline \multirow{4}{*}{ S2 } & W0 & $5854.82 \mathrm{c}$ & $11,663.78 c$ & $5366.74 b$ & $13,387.89 b$ & $-8.34 \%$ & $+14.78 \%$ \\
\hline & W1 & $5759.94 \mathrm{~cd}$ & $11,732.04 \mathrm{c}$ & $3082.55 f$ & $7435.41 \mathrm{~g}$ & $-46.48 \%$ & $-36.62 \%$ \\
\hline & W2 & 5638.14de & $11,299.05 \mathrm{~d}$ & $2849.45 \mathrm{~g}$ & $6704.38 \mathrm{~h}$ & $-49.46 \%$ & $-40.66 \%$ \\
\hline & W3 & $5590.19 \mathrm{e}$ & $11,773.17 \mathrm{c}$ & $2767.87 \mathrm{~g}$ & $6722.17 \mathrm{~h}$ & $-50.49 \%$ & $-42.90 \%$ \\
\hline \multirow{4}{*}{ S3 } & W0 & $7643.98 b$ & $15,915.8 \mathrm{~b}$ & $7692.66 a$ & $18,593.89 a$ & $+0.64 \%$ & $+16.83 \%$ \\
\hline & W1 & $7844.88 \mathrm{a}$ & $16,267.21 a$ & $3834.98 \mathrm{~d}$ & $11,243.06 c$ & $-51.11 \%$ & $-30.89 \%$ \\
\hline & W2 & 7746.26ab & $15,810.72 b$ & $3667.53 \mathrm{e}$ & $9956.62 d$ & $-52.65 \%$ & $-37.03 \%$ \\
\hline & W3 & $7628.45 b$ & $16,040.77 a b$ & $3972.49 c$ & $9276.96 \mathrm{e}$ & $-47.93 \%$ & $-42.17 \%$ \\
\hline \multicolumn{2}{|c|}{ W } & ns & ns & ns & $* *$ & $* *$ & ** \\
\hline \multicolumn{2}{|c|}{ S } & $*$ & $* *$ & $* *$ & $* *$ & $* *$ & ** \\
\hline \multicolumn{2}{|c|}{$\mathrm{W} \times \mathrm{S}$} & ns & ns & ns & $* *$ & $* *$ & $* *$ \\
\hline
\end{tabular}

Note: W0, W1, W2, and W3 represent the winter irrigation quota of $0,3000,3600$, and $4200 \mathrm{~m}^{3} \cdot \mathrm{hm}^{-2}$, respectively, whereas S1, S2, and S3 represent the initial salt concentrations of $6.20,10.17$, and $12.23 \mathrm{~g} \cdot \mathrm{kg}^{-1}$, respectively. Shared lowercase letters within a column in the table indicate no significant difference between treatments $(p>0.05)$, ** indicates extremely significant correlation of indicators $(p<0.01), *$ indicates significant correlation of indicators $(p<0.05)$, the same as below.

For saline cotton field S1, the total soil salt contents of the $0-40$ and $0-100 \mathrm{~cm}$ soil layers under the $\mathrm{W} 1, \mathrm{~W} 2$, and W3 treatments were not significantly different $(p>0.05)$, and the desalination rate of the $0-40$ and $0-100 \mathrm{~cm}$ soil layers was $\mathrm{W} 1>\mathrm{W} 3>\mathrm{W} 2$ and $\mathrm{W} 3>\mathrm{W} 2>\mathrm{W} 1$, respectively. For saline cotton field S2, the total soil salt contents of the $0-40$ and $0-100 \mathrm{~cm}$ soil layers under treatment W1 were significantly different from those under W2 and W3 treatments $(p<0.05)$, with no significant differences between W2 and W3 $(p>0.05)$, and the desalination rate of the $0-40$ and $0-100 \mathrm{~cm}$ soil layers all showed the order W3 $>$ W2 $>$ W1. For saline cotton field S3, the total soil salt contents of the 0-40 and 0-100 cm soil layers under the W1, W2, and W3 treatments were significantly different $(p<0.05)$, with the desalination rates being in the order $\mathrm{W} 2>\mathrm{W} 1>\mathrm{W} 3$ and $\mathrm{W} 3>\mathrm{W} 2>\mathrm{W} 1$, respectively. The average desalination rates of $0-40$ and $0-100 \mathrm{~cm}$ soil layers in saline cotton fields under different winter irrigation rate treatments were W2 $(50.76 \%)>\mathrm{W} 1(50.38 \%)>\mathrm{W} 3(50.01 \%)$ and W3 $(43.81 \%)>$ W2 $(41.15 \%)>$ W1 $(36.96 \%)$, respectively (Table 5$)$.

To sum up, the degree of soil salt reduction in the same salinized cotton field differed between the different winter irrigation rates. The desalination effect of the $0-40 \mathrm{~cm}$ soil layer was greater than that of the 0-100 cm soil layer under the leaching effect of W1, W2, and W3 treatments in different salinized cotton fields, whereas the desalination effect on the soil layer 0-100 $\mathrm{cm}$ increased with the increase in winter irrigation rate. The greater the irrigation rate in winter, the easier it was to wash the soil salt into the deep soil layers. 
Table 6. Correlation analysis of indexes under winter irrigation of cotton fields with differential salinities.

\begin{tabular}{|c|c|c|c|c|c|c|c|c|c|c|}
\hline \multirow[t]{2}{*}{ Control Variate } & \multirow{2}{*}{\multicolumn{2}{|c|}{ Index }} & \multirow[t]{2}{*}{ Yield } & \multirow[t]{2}{*}{ Emergence Rate } & \multicolumn{2}{|c|}{ Freezing-Thawing Indices } & \multicolumn{2}{|c|}{$\begin{array}{c}\text { Soil Water Content } \\
\text { before Spring Plowing }\end{array}$} & \multicolumn{2}{|c|}{$\begin{array}{l}\text { Total Soil Salt Content } \\
\text { before Spring Plowing }\end{array}$} \\
\hline & & & & & Freezing Index & Thawing Index & $0-40 \mathrm{~cm}$ & $0-100 \mathrm{~cm}$ & $0-40 \mathrm{~cm}$ & $0-100 \mathrm{~cm}$ \\
\hline \multirow{10}{*}{ No } & \multirow{2}{*}{\multicolumn{2}{|c|}{$\begin{array}{c}\text { Yield } \\
\text { Emergence rate }\end{array}$}} & 1 & & & & & & & \\
\hline & & & $0.99 * *$ & 1 & & & & & & \\
\hline & Freezing- & Freezing index & $0.86^{* *}$ & $0.87^{* *}$ & 1 & & & & & \\
\hline & thawing indices & Thawing index & $-0.87^{* *}$ & $-0.87^{* *}$ & $-0.82 * *$ & 1 & & & & \\
\hline & Soil water content & $0-40 \mathrm{~cm}$ & $0.84 * *$ & $0.85 * *$ & $0.91 * *$ & $-0.85^{* *}$ & 1 & & & \\
\hline & before spring plowing & $0-100 \mathrm{~cm}$ & $0.85^{* *}$ & $0.86^{* *}$ & $0.88^{* *}$ & $-0.86^{* *}$ & $0.97^{* *}$ & 1 & & \\
\hline & Total soil salt before & $0-40 \mathrm{~cm}$ & $-0.90^{* *}$ & $-0.91 * *$ & $-0.82 * *$ & $0.89^{* *}$ & $-0.92^{* *}$ & $-0.94 * *$ & 1 & \\
\hline & spring plowing & $0-100 \mathrm{~cm}$ & $-0.94^{* *}$ & $-0.95^{* *}$ & -0.85 ** & $0.89^{* *}$ & $-0.92^{* *}$ & $-0.94 * *$ & $0.99 * *$ & 1 \\
\hline & \multirow{2}{*}{\multicolumn{2}{|c|}{$\begin{array}{l}\text { Initial salt concentration } \\
\text { Winter irrigation rate }\end{array}$}} & $-0.81^{* *}$ & $-0.82 * *$ & $-0.56^{* *}$ & $0.66^{* *}$ & $-0.50^{* *}$ & $-0.50 * *$ & $0.65^{* *}$ & $0.72 * *$ \\
\hline & & & $0.54^{* *}$ & $0.54^{* *}$ & $0.76^{* *}$ & $-0.63 * *$ & $0.85^{* *}$ & $0.85^{* *}$ & $-0.71^{* *}$ & $-0.67^{* *}$ \\
\hline & \multicolumn{2}{|c|}{ Yield } & 1 & & & & & & & \\
\hline & \multicolumn{2}{|c|}{ Emergence rate } & $0.85^{* *}$ & 1 & & & & & & \\
\hline Initial salt & Freezing- & Freezing index & $0.16 *$ & $0.16 *$ & 1 & & & & & \\
\hline content and & thawing indices & Thawing index & -0.02 & 0.01 & 0.13 * & 1 & & & & \\
\hline Winter & Soil water content & $0-40 \mathrm{~cm}$ & $-0.29 * *$ & $-0.24 * *$ & -0.11 & 0.30 * & 1 & & & \\
\hline \multirow{3}{*}{ irrigation rate } & before spring plowing & $0-100 \mathrm{~cm}$ & 0.10 & $0.14 *$ & $-0.50^{* *}$ & -0.09 & $0.49 * *$ & 1 & & \\
\hline & Total soil salt before & $0-40 \mathrm{~cm}$ & 0.03 & -0.01 * & $0.72 * *$ & 0.15 * & -0.171 & $-0.40^{* *}$ & 1 & \\
\hline & spring plowing & $0-100 \mathrm{~cm}$ & $-0.22 * *$ & $-0.25^{* *}$ & $0.62^{* *}$ & 0.09 & -0.09 & $-0.48^{* *}$ & $0.87^{* *}$ & 1 \\
\hline
\end{tabular}

Note: The first set of correlations (above the horizontal line) represents the Pearson correlation analysis and the value represents Pearson correlation coefficient. The second set of correlations (under the horizontal line) means partial correlation or net correlation analysis and the value represents the partial correlation coefficient. ${ }^{* *}$ indicates extremely significant correlation of indicators $(p<0.01), *$ indicates significant correlation of indicators $(p<0.05)$, 
3.4. Effects of Different Winter Irrigation Rates on Cotton Seedling Emergence and Yield in Cotton Fields with Different Salinity Levels

The values for seedling emergence and yield of cotton on salinized soil in the year following winter irrigation are shown in Figure 7. When the management conditions of the cotton growth period were consistent, the seedling emergence rate and yield of cotton under winter irrigation treatment were higher than those of the corresponding control treatment without winter irrigation (W0), and the difference was significant $(p<0.05)$. The average seedling emergence rate of cotton in S1, S2, and S3 salinized cotton fields under winter irrigation was $92.82 \%, 81.82 \%$, and $58.91 \%$, respectively, which represented an increase of $25.84 \%, 34.90 \%$, and $64.91 \%$, respectively, compared with the control treatment without winter irrigation. The average yield of cotton in the S1, S2, and S3 salinized fields under winter irrigation was $5725.46,5091.80$, and $3628.82 \mathrm{~kg} \cdot \mathrm{hm}^{-2}$, respectively, which increased by $25.37 \%, 35.27 \%$, and $67.04 \%$, respectively, compared with the control treatment without winter irrigation (Figure 7). Under the same winter irrigation rate, there were significant differences in the emergence rate and yield of S1, S2, and S3 of salinized cotton fields $(p<0.05)$, with the emergence rate and yield of cotton decreasing with increase in salinization degree, whereas the incremental effect on emergence rate and yield of cotton increased with an increase in degree of salinization. For saline cotton field S1, the values of seedling emergence and yield of cotton under winter irrigation rate W1 were significantly different from those under W2 and W3 treatments $(p<0.05)$, with no significant differences between $\mathrm{W} 2$ and W3 $(p>0.05)$. For saline cotton fields S2 and S3, the seedling emergence and yield of cotton under the winter irrigation rates W1, W2, and W3 were significantly different $(p<0.05)$. Compared with the control treatment without winter irrigation (W0), the emergence rate of cotton under winter irrigation rates $\mathrm{W} 1, \mathrm{~W} 2$, and $\mathrm{W} 3$ increased by $29.14 \%, 44.36 \%$, and $52.16 \%$ on average, respectively, and the yield increased by $29.36 \%, 45.00 \%$, and $53.32 \%$ on average, respectively. Under different winter irrigation rates in the same saline cotton field, the emergence rate and yield of cotton increased with an increase in winter irrigation rate, and the incremental change in emergence rate and yield of cotton also increased with increased winter irrigation rate. Among all the treatments, the emergence rate and yield of cotton under the W2S1 treatment were the highest $\left(95.12 \%, 5913.15 \mathrm{~kg} \cdot \mathrm{hm}^{-2}\right.$, respectively) and the emergence rate and yield of cotton under the W1S3 treatment were the lowest $\left(50.49 \%, 3124.52 \mathrm{~kg} \cdot \mathrm{hm}^{-2}\right.$, respectively), whereas the incremental effects on emergence rate and yield of cotton under the W3S3 treatment were the highest $\left(68.04 \%, 4198.14 \mathrm{~kg} \cdot \mathrm{hm}^{-2}\right.$, respectively) compared with those without winter irrigation. After winter irrigation, cotton emergence rate and yield were significantly correlated with winter irrigation rate and soil salinization level $(p<0.01)$, and cotton emergence rate was significantly correlated with yield $(p<0.01)$ (Table 6).

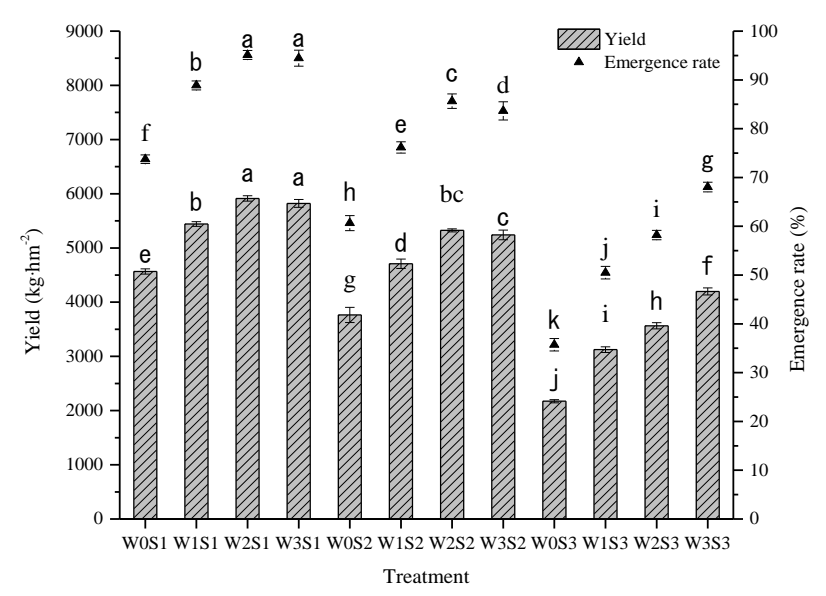

Figure 7. Seedling emergence rate and yield of cotton on salinized soil under winter irrigation. 
In conclusion, winter irrigation promoted the emergence rate and yield of cotton on salinized soil in the following year, with the larger the irrigation (leaching) rate, the greater the increase in cotton emergence and yield associated with winter irrigation. However, the effect of the same winter irrigation rate on yield had different influences on the cotton yield, depending on the degree of salinization of the field, with the effect of winter irrigation on cotton seedling emergence rate and yield increase being greater in severely salinized cotton fields. Therefore, the appropriate winter irrigation rate for raising the seedling emergence rate and yield to the target value depended on the salinization degree of the cotton fields.

\subsection{Correlation Analysis and Data Fitting}

\subsubsection{Correlation Analysis}

The correlation between soil moisture, temperature, salinity, and cotton growth index, namely the emergence rate and yield, of crops grown in cotton fields with different salinities under different rates of winter irrigation are shown in Table 6 . In the simple correlation analysis without control variables, all indexes were significantly correlated $(p<0.01)$, and the correlation coefficient values were all greater than 0.80 . Cotton yield was positively correlated with seedling emergence rate, the soil water content before spring plowing, and the freezing index, whereas it was negatively correlated with the total soil salt content before spring plowing and the thawing index. The seedling emergence rate of cotton was negatively correlated with the total soil salt content before spring plowing and the thawing index, but positively correlated with soil water content before plowing and the freezing index. The soil freezing index was significantly negatively correlated with the total soil salt content before spring cultivation and the thawing index, but positively correlated with the soil water content before spring cultivation (Table 6). The soil thawing index was significantly negatively correlated with soil water content before spring cultivation, while positively correlated with total soil salt content before spring cultivation.

The soil water content before spring tillage was significantly negatively correlated with the total soil salt content before spring tillage. When the control variable was "winter irrigation rate and initial salt content" for partial correlation analysis, the correlation and correlation coefficient of each index changed greatly. The cotton yield was significantly positively correlated with the seedling emergence rate $(p<0.01)$, the partial correlation coefficient decreased to 0.85 , positively correlated with freezing index $(p<0.05)$, negatively correlated with $0-40 \mathrm{~cm}$ water content and 0-100 $\mathrm{cm}$ total salt content before spring plowing, with the partial correlation coefficient being less than 0.30 . The seedling emergence rate of cotton was positively correlated with the freezing index $(p<0.05)$, negatively correlated with $0-40 \mathrm{~cm}$ soil water content and $0-100 \mathrm{~cm}$ soil salt content before spring plowing $(p<0.01)$, positively correlated with $0-100 \mathrm{~cm}$ soil water content, and negatively correlated with $0-40 \mathrm{~cm}$ soil salt content before spring plowing $(p<0.05)$. The soil freezing index was positively correlated with the thawing index $(p<0.05)$, negatively correlated with $0-100 \mathrm{~cm}$ soil water content before spring plowing $(p<0.01)$, and positively correlated with total soil salt content before spring plowing $(p<0.01)$; The soil thawing index was positively correlated with water content and total salt content in the $0-40 \mathrm{~cm}$ soil layer before spring plowing $(p<0.05)$ (Table 6$)$.

Therefore, the multiple correlations between winter irrigation rate and initial salt content in the cotton field affected the correlation between soil moisture, temperature, salinity, and cotton growth index in the following year. The correlation between the indexes with different results of simple correlation analysis and partial correlation analysis represented pseudo-correlation, and there was no true correlation, which might be due to the difficulty of quantitative control of the field environment and the lack of test samples. However, partial correlation analysis showed that the net correlation between water temperature and salinity was still significant after excluding the effects of winter irrigation rate and initial salt content on the variables. The results showed that there was a significant correlation between seedling emergence and soil moisture content and salt content $(p<0.05)$, and there 
was still a significant correlation between cotton emergence rate and yield $(p<0.01)$ (Table 6). To sum up, winter irrigation could strengthen the multiple correlations between cotton seedling emergence and yield, and between soil moisture, temperature, and salinity, which were beneficial for influencing cotton growth index by affecting soil physical and chemical indexes.

\subsubsection{Data Fitting}

Based on the test results, the relationship between the seedling emergence rate and cotton yield and the initial salt content of the winter irrigation test control factors of the cotton field and the rate of winter irrigation were fitted, respectively. The fitting method was nonlinear surface fitting, and the selected fitting function was Poly 2D. The results of the fitting are shown in Equation (5) and (6), and Figure 8 . The significance test of the equation-of-best-fit showed that the determination coefficients of determination $\left(\mathrm{r}^{2}\right)$ of the fitting results were all greater than 0.95 , indicating that the predicted index and the measured index showed a very high degree of fitting. The fitting relational expression could truly reflect the non-linear correlation between the emergence rate, yield, and the control factor of the winter irrigation experiment, which were the initial salt content of the cotton field and the winter irrigation rate, which had certain practical guidance significance for winter irrigation. It could be seen from the fitting results that the emergence rate and yield of cotton were significantly correlated with both initial soil salt concentration and winter irrigation rate $(p<0.01)$. The emergence rate of cotton was significantly positively correlated with the yield $(p<0.01)$. However, the correlation coefficients between emergence rate and yield in cotton fields with low salinity and without winter irrigation were also significantly higher than those in fields with higher salinity. In summary, the winter irrigation treatment is indispensable for salinized cotton fields, but the appropriate winter irrigation rate for salinized cotton fields with different levels of salinity to obtain high seedling rate and cotton yield was inconsistent.

$$
\begin{aligned}
& Z_{1}=78.07+2.55 \times \alpha+4.84 \times 10^{-4} \times \beta-0.58 \times \alpha^{2}+5.90 \times 10^{-7} \times \beta^{2} \\
& +3.75 \times 10^{-4} \times \alpha \times \beta \quad\left(r^{2}=0.9810\right) \\
& Z_{2}=4297.37+310.72 \times \alpha-3.95 \times 10^{-2} \times \beta-45.40 \times \alpha^{2}+5.30 \times 10^{-5} \times \beta^{2} \\
& +2.46 \times 10^{-2} \times \alpha \times \beta \quad\left(r^{2}=0.9754\right)
\end{aligned}
$$

where $Z_{1}$ is he emergence rate, $\% ; Z_{2}$ is the yield, $\mathrm{kg} \cdot \mathrm{hm}^{-2} ; \alpha$ is the initial salt concentration, $\mathrm{g} \cdot \mathrm{kg}^{-1}$; $\beta$ is the winter irrigation rate, $\mathrm{m}^{3} \cdot \mathrm{hm}^{-2}$.

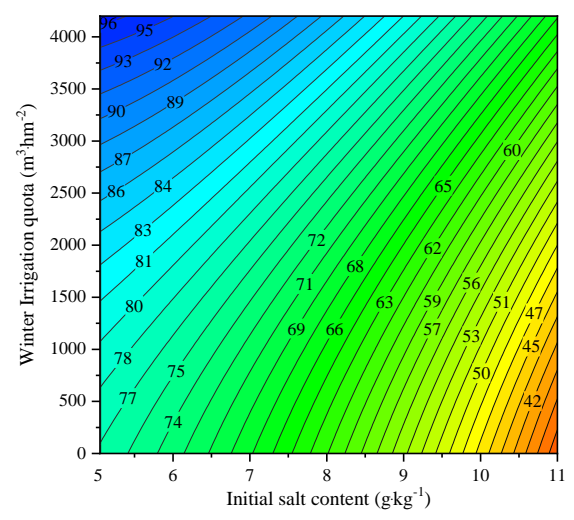

(a)

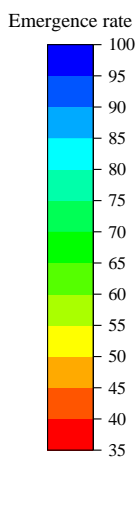

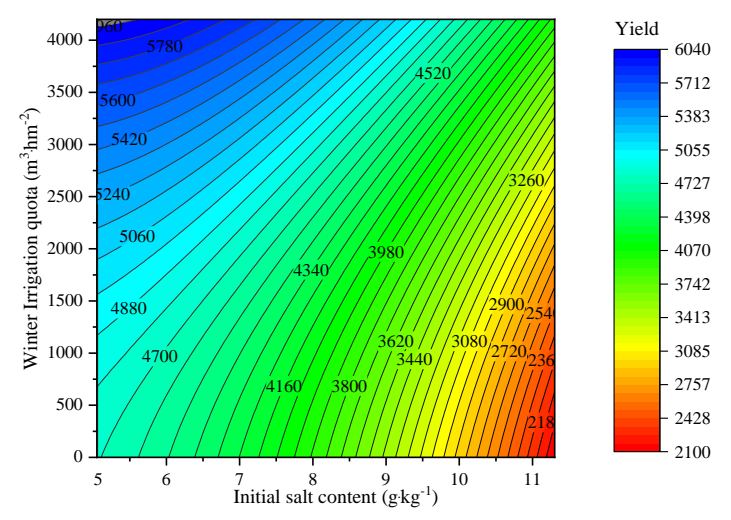

(b)

Figure 8. The fitting relation diagram of cotton growth index and winter irrigation control variables.

(a) Emergence rate; (b) Yield. 


\section{Discussion}

Seasonal freezing and thawing are the main driving factors for the occurrence of soil salinization in arid areas. Freezing and thawing can change soil structure, as well as physical and chemical properties, and affect the spatial and temporal changes of soil moisture, temperature, and salt [24,25]. Temperature is the driving force of soil water and salt migration under freezing and thawing conditions [26]. The freezing process results in a rapid decrease in temperature, and the soil water freezes, while the ablation process heats up rapidly to thaw and evaporate the frozen water. The large variation in soil temperature is not conducive to water content and soil moisture conservation. Yao et al. [23] and $\mathrm{Fu}$ et al. [27] reported that irrigation could improve soil heat capacity, whereas straw mulch hindered heat transfer between the soil and the atmosphere, with irrigation and surface mulch having a double blocking effect on soil temperature, which could significantly reduce the variation in ground temperature. Li et al. [13] showed that soil texture determines soil water-holding capacity and thermal diffusivity, whereas soil moisture and temperature had strong mutual influences and restriction relationships.

Contrary to previous studies, the current research found, in studies of soil temperature variation in soils of the same texture and different degrees of salinization under the same rates of winter irrigation, that leaching was weaker in these soils than in the control treatment soils without winter irrigation. Under winter irrigation treatment of mildly, moderately, and severely salinized cotton fields, the values of the freezing index in the $0-40 \mathrm{~cm}$ soil layer decreased by $42.92 \%, 32.76 \%$, and $19.17 \%$ on average, respectively, and the values of the thawing index decreased by $11.57 \%, 15.53 \%$, and $20.23 \%$ on average, respectively. The soil salinization level had a significant influence on the freezing-thawing index $(p<0.05)$, and winter irrigation had a greater influence on the freezing index of the mildly salinized test group and on the thawing index of the severely salinized test group. This is because the soil salt can reduce the freezing temperature of the soil water, increase the soil moisture content during freezing period, and indirectly affect the soil temperature. It was found that the influence of winter irrigation on the freezing index was significantly greater than that on the thawing index. This observation was because the soil gradually froze after the end of the winter irrigation. The water in the frozen soil layer under winter irrigation was significantly higher in the $0-40 \mathrm{~cm}$ layer, and the residual winter irrigation water in the soil layer during the thawing of the $0-40 \mathrm{~cm}$ layer was significantly lower than that when it was frozen. Therefore, the effect of winter irrigation on the soil temperature during the thawing period was weakened.

During the freezing-thawing period, soil water movement was strongly coupled with heat flow and salt migration [28]. Chen et al. [29] found that, when soil freezes, the salt in the unfrozen layer moves from freezing edge to freezing edge, with water under the action of soil water potential, and the salt in the frozen layer, far away from the freezing edge, moves downward, and the frozen soil layer showed desalination. Wu et al. [30] believed that, during freezing, the salt was mainly influenced by convection, and that, under the effect of a temperature gradient, the salt moved from the warm end to the cold end, along with the water flow, leading to the frozen layer of soil accumulating salt. Research by Cui et al. [31] showed that frozen stratified salt or desalination depends on the soil salt gradient and the co-saturation point of different salts. When the concentration gradient of the soil solution before freezing is positive, the frozen layer is prone to salt accumulation; otherwise, the frozen layer desalts. The current study found that the changes in soil water and salt content in saline cotton fields over time were similar under winter irrigation. The water content of the frozen soil layer was increased by winter irrigation, and the concentration gradient of the solution in the $0-20 \mathrm{~cm}$ frozen layer after $15 \mathrm{~d}$ of irrigation was positive, showing salt accumulation, whereas the concentration gradient of the solution in the $0-20 \mathrm{~cm}$ frozen layer during the stable freezing period was negative, showing desalination. This result is consistent with the research results of Cui and colleagues [31], which proves that the salt concentration change in the frozen soil layer is related to the salt gradient of the soil solution before freezing. 
Winter irrigation has a good effect on soil moisture conservation and salt suppression, washing soil salt deep into the soil layers and inhibiting soil salt return caused by evaporation in the following year, as well as providing good soil water and salt conditions for crop growth [32]. In the present study, it was found that the distribution and content of soil water and salt in the cotton fields with different degrees of salinity were different before spring tillage under different winter irrigation rates. The water-accumulating effect of soil treated before spring tillage was significantly reduced compared with that $7 \mathrm{~d}$ after winter irrigation, but the desalting effect was similar to that achieved $7 \mathrm{~d}$ after winter irrigation. Under the same winter irrigation rate, the water content in the $0-40 \mathrm{~cm}$ soil layer of mildly, moderately, and severely salinized cotton fields changed by $-6.27 \%,-0.97 \%$, and $5.32 \%$ on average, respectively, and that in the $0-100 \mathrm{~cm}$ soil layer increased by $11.31 \%, 22.68 \%$, and $29.38 \%$ on average, respectively. Under the same winter irrigation rate, the total salt content in the $0-40 \mathrm{~cm}$ soil layer of mildly, moderately, and severely salinized cotton field decreased by $51.77 \%, 48.81 \%$, and $50.56 \%$ on average, respectively, and that in the $0-100 \mathrm{~cm}$ soil layer decreased by $45.17 \%, 40.06 \%$, and $36.69 \%$ on average, respectively.

To summarize, the desalination effect in the $0-40 \mathrm{~cm}$ soil layer was greater than that in the $0-100 \mathrm{~cm}$ soil layer. When the winter irrigation rate was greater than $3600 \mathrm{~m}^{3} \cdot \mathrm{hm}^{-2}$, the moisture content of soil layer $0-100 \mathrm{~cm}$ increased by more than $20 \%$ and the desalination exceeded $40 \%$. This conclusion was consistent with the research results proposed by Zhang et al. [33] that a winter irrigation rate of $3600 \mathrm{~m}^{3} \cdot \mathrm{hm}^{-2}$ can provide a suitable water and salt environment for cotton seedling emergence in the following year, whereas Yang et al. [17] proposed that the appropriate winter irrigation rate for cotton fields in southern Xinjiang should be $1800-3600 \mathrm{~m}^{3} \cdot \mathrm{hm}^{-2}$, and Li et al. [34] indicated that the total irrigation rate should be within $3750 \mathrm{~m}^{3} \cdot \mathrm{hm}^{-2}$ for the winter and spring irrigation in southern Xinjiang. The winter irrigation rate concluded from the present study was slightly higher than the optimal winter irrigation rate of $3000 \mathrm{~m}^{3} \cdot \mathrm{hm}^{-2}$ for cotton fields in northern Xinjiang proposed by Chen et al. [35] and Mou et al. [16]. The present results also showed that the salt leaching effect of winter irrigation is more significant than the effect of increasing water. When the irrigation rate was high, the soil salt could be leached to a depth that could effectively prevent the return of the soil salt. The existing literature had not focused on the effect of soil salinization on the effect of water content and salt leaching in winter irrigation, but the current study carried out field winter irrigation experiments in mildly, moderately, and severely saline cotton fields. In the present study, it was found that, the higher the degree of soil salinization, the stronger the water suction and the more difficult it was for soil salt to be leached to deep layers. Therefore, the water content in severely saline cotton fields increased more, whereas the desalination effect in lightly saline cotton fields was greater.

The emergence rate and yield of cotton in the year following winter irrigation are the most direct indicators of the effect of winter irrigation. Soil water and salt contents directly affected the emergence rate of cotton, while the emergence rate and yield were significantly positively correlated under the standard crop management conditions during the growth period. Tatiana et al. [36] studied the effect of supplementary irrigation on water status and productivity of avocado trees during the winter drought season, and found that the cumulative fruit yield of avocado increased by $18.2 \%$ under $2545 \mathrm{~m}^{3} \cdot \mathrm{hm}^{-2}$ winter irrigation, which was also beneficial for increased fruit yield. Ma et al. [37] studied the effect of winter irrigation under different irrigation rates, and found that winter irrigation was consumed up to $75-85 \mathrm{~d}$ after winter irrigation, and that there was no significant difference in winter wheat yield under different winter irrigation rates, which had no effect on crop yield. Zhao et al. [38] proposed that the appropriate amount of winter irrigation in northern Xinjiang cotton fields could provide suitable water and salt conditions for cotton seedling emergence in the following year. The results from the current study showed that cotton yield increased by $10.66 \%$ when the winter irrigation rate was $3000 \mathrm{~m}^{3} \cdot \mathrm{hm}^{-2}$ under drip irrigation, compared with that achieved without winter irrigation. This study found that the emergence rate and yield, respectively, from different saline-alkali cotton fields under winter irrigation were as follows: slightly saline cotton fields $\left(92.82 \%, 5725.46 \mathrm{~kg} \cdot \mathrm{hm}^{-2}\right.$, respectively) $>$ moderately saline cotton fields $\left(81.82 \%, 5091.80 \mathrm{~kg} \cdot \mathrm{hm}^{-2}\right)>$ severely saline cotton fields $\left(58.91 \%, 3628.82 \mathrm{~kg} \cdot \mathrm{hm}^{-2}\right)$. 
Compared with the control treatment without winter irrigation, the average relative (\%) increases in emergence and yield resulting from winter irrigation were as follows: severely saline cotton fields $(64.91 \%, 67.04 \%$, respectively) $>$ moderately saline cotton fields $(34.90 \%, 35.27 \%)>$ slightly saline cotton fields $(25.87 \%, 25.37 \%)$. Winter irrigation treatment promoted the emergence rate and yield of cotton in the following year. The emergence rate and yield of cotton increased with the increasing winter irrigation rate and the decrease in soil salinization. This conclusion is in line with the research results of Zhao et al. [38].

Winter irrigation can significantly change the natural distribution of soil salt before sowing in the following year, effectively leaching and reducing the salt content in the upper soil layers, and positively affecting the plant population index and the yield of cotton under drip irrigation. The previous studies did not consider the effect of winter irrigation on the physiological indexes of crops in the following year based on the salinity of cotton fields. However, the present study pointed out that the response of emergence and yield to winter irrigation was different, depending on the salinity level, and there was no significant difference in seedling emergence rate or yield between slightly and moderately salinized cotton fields under the treatments of $3600 \mathrm{~m}^{3} \cdot \mathrm{hm}^{-2}$ or $4200 \mathrm{~m}^{3} \cdot \mathrm{hm}^{-2}$ winter irrigation rate $(p>0.05)$, although the seedling emergence rate and yield of severely salinized cotton fields increased significantly with the increased winter irrigation rate. The emergence rates and yields of slightly and moderately salinized cotton fields were significantly lower than those of severe salinized cotton fields $(p<0.05)$, and the optimal winter irrigation rates in different salinized cotton fields were different. This was because the effect of soil water content and salt leaching varied between fields with different salinities, with the emergence of cotton seedlings being greatly affected by salt content. Under the standard crop management conditions, the cotton yield was significantly correlated with the seedling emergence rate $(p<0.01)$. Therefore, the response of emergence and yield in cotton fields of different salinities under winter irrigation and leaching were different.

To sum up, water, temperature, and salt in soil interacted under the effects of winter irrigation, with the soil temperature, water and salt in cotton fields with different salinity levels increasing and decreasing under the action of different winter irrigation rates. Based on the results from these field experiments, the present study was suitable for estimating the relationship between different winter irrigation rates on cotton emergence rate and yield in the following year on soils of different salinity levels. These results had both theoretical significance and practical value for determining appropriate winter irrigation rates for actual production on salinized soils

\section{Conclusions}

Winter irrigation stabilized the soil temperature and reduced the freeze-thaw index of the soil. Additionally, the winter irrigation rate and soil salinization level had significant influences on soil temperature $(p<0.05)$. The heat conservation effect of winter irrigation increased with increasing winter irrigation rate and salinization degree, and the relative temperature change in the $0-40 \mathrm{~cm}$ soil layer was significantly higher than that of the $40-100 \mathrm{~cm}$ soil layer $(39.82 \%, 28.49 \%$, respectively). Winter irrigation had the greatest effect on the freezing index of the mildly saline soil (the freezing index decrease rate was $42.92 \%$ ) and on the thawing index of the severely saline soil (the thawing index decrease rate was $20.23 \%$ ).

Winter irrigation affected the temporal and spatial migration of soil water and salt in salinized cotton fields, the salt concentration change in the frozen soil layer was related to the salt gradient of the soil solution before freezing. When the concentration gradient of the soil solution before freezing was positive, the frozen layer was prone to salt accumulation; otherwise, the frozen layer desalted. Winter irrigation increased the moisture content of the frozen soil layer, and the saturated moisture layer appeared on the seventh day after winter irrigation and the initial evaporation period. Soil water content and total salt content before spring plowing were significantly correlated with the winter irrigation rate and the soil salinization degree $(p<0.05)$. The effect of winter irrigation and leaching on soil water content and salt leaching was greater in heavily salinized cotton fields, and the desalination 
effect in the 0-40 cm soil layer was greater than that in the $0-100 \mathrm{~cm}$ soil layer. When the irrigation rate was greater than $3600 \mathrm{~m}^{3} \cdot \mathrm{hm}^{-2}$, it could meet the requirement for the water increase in the $0-100 \mathrm{~cm}$ soil layer in cotton fields with different salinities was greater than $20 \%$ and the desalination rate exceeded $40 \%$.

Winter irrigation improved the emergence rate and yield of cotton, and the soil salinization degree and winter irrigation rates were significantly correlated with the emergence rate and yield of cotton fields in the following year $(p<0.01)$. There was no significant difference in seedling emergence rate and yield between slightly and moderately salinized cotton fields under the treatment of $3600 \mathrm{~m}^{3} \cdot \mathrm{hm}^{-2}$ or $4200 \mathrm{~m}^{3} \cdot \mathrm{hm}^{-2}$ winter irrigation rates $(p>0.05)$, whereas the seedling emergence rate and yield of cotton in severely salinized cotton fields increased significantly with the increase in winter irrigation rate. The degrees of response of physiological indexes, such as seedling emergence and yield, in cotton fields with different salinities to different winter irrigation rates were different. The curve-fitting relationships (Equation (5) and (6)) could be combined to guide winter irrigation rates to determine the optimal winter irrigation rates in cotton fields with different salinities.

Author Contributions: Conceptualization: H.L.; methodology: L.L. and H.L.; software: L.L.; resources: H.L; data curation: L.L. and H.L.; writing—original draft preparation: L.L.; writing—review and editing: H.L.; visualization: L.L. and E.L.; supervision: H.L., X.H. and G.Y.; project administration: H.L. and X.H.; funding acquisition: H.L. All authors have read and agreed to the published version of the manuscript.

Funding: We acknowledge the financial support from the National Natural Science Foundation Program (U1803244, 51669029 , 2020DB01) and the National Key Development Program (2016YFC0501406). The founding sponsors had no role in the design of the study; in the collection, analyses or interpretation of data; in the writing of the manuscript; or in the decision to publish the results.

Acknowledgments: We thank the editors and anonymous reviewers for their fruitful comments. We also thank International Science Editing (http://www.internationalscienceediting.com) for editing this manuscript.

Conflicts of Interest: The authors declare no conflict of interest.

\section{References}

1. Hu, M.F.; Tian, C.L.; Zhao, Z.Y.; Wang, L.X. Salinization causes and research progress of technologies improving saline-alkali soil in Xinjiang. J. Northwest A F Univ. (Nat. Sci. Ed.) 2012, 40, 111-117.

2. Tian, C.L.; Mai, W.X.; Zhao, Z.Y. Study on key technologies of ecological management of saline alkali land in arid area of Xinjiang. Acta Ecol. Sin. 2016, 36, 7064-7068.

3. Liu, B.; Zhao, W.; Wen, Z.; Yang, Y.; Chang, X.; Yang, Q.; Meng, Y.; Liu, C. Mechanisms and feedbacks for evapotranspiration-induced salt accumulation and precipitation in an arid wetland of China. J. Hydrol. 2018, 568, 403-415. [CrossRef]

4. Wu, D.Y.; Zhou, X.Y.; Jiang, X.Y. Water and Salt Migration with Phase Change in Saline Soil during Freezing and Thawing Processes. Groundwater 2017, 56, 742-752. [CrossRef] [PubMed]

5. Hu, H.C.; Tian, F.Q.; Zhang, Z.; Yang, P.J.; Ni, G.H.; Li, B. Soil salt leaching in non-growth period and salinity dynamics under mulched drip irrigation in arid area. J. Hydraul. Eng. 2015, 46, 1037-1046.

6. Liang, Y.J.; Li, X.Y.; Zheng, J.Y.; Gong, Z.L.; Ai, X.T.; Guo, J.P.; Maimaiti, M.M.; Wang, J.D. Overview of Cotton Industry Situation and Existing Problems and Strategies in Xinjiang in 2019. Cotton Sci. 2020, 42, 14-20.

7. Zhang, K.W.; Song, J.L.; Chen, X.G.; Yin, T.T.; Liu, C.B.; Li, K.P.; Zhang, J.R. Expression of the Thellungiella halophila vacuolar $\mathrm{H}^{+}$-pyrophosphatase gene (TsVP) in cotton improves salinity tolerance and increases seed cotton yield in a saline field. Euphytica 2016, 211, 231-244. [CrossRef]

8. Wang, C.X.; Wang, Q.J.; Liu, J.J.; Su, L.J.; Dan, Y.Y.; Zhuang, L. Effects of mineralization of irrigation water and soil salinity on cotton emergence rate in Southern Xinjiang Uygur Autonomous Region of China. Trans. CSAE 2010, 26, 28-33.

9. Zhi, Z.; Hu, H.C.; Tian, F.Q.; Hu, H.P.; Yao, X.H.; Zhong, R.S. Soil salt distribution under mulched drip irrigation in an arid area of northwestern China. J. Arid Environ. 2014, 104, 23-33.

10. Guan, Z.L.; Jia, Z.F.; Zhao, Z.Q.; You, Q.Y. Dynamics and Distribution of Soil Salinity under Long-Term Mulched Drip Irrigation in an Arid Area of Northwestern China. Water 2019, 11, 1125. [CrossRef] 
11. He, P.R.; Zhang, F.C.; Hou, X.H.; Liu, N.J.; Meng, X.C.; Zhang, C.Y.; Cheng, H.L. Effects of Soil Water Regulation on Cotton Yield and Soil Water-Salt Distribution Under Drip Irrigation in Southern Xinjiang. Res. Soil Water Conserv. 2020, 27, 84-92.

12. Wu, J.; Li, H.; Niu, J.; Liu, T.; Miao, S. Water Uptake Patterns of Alfalfa under Winter Irrigation in Cold and Arid Grassland. Water 2020, 12, 1093. [CrossRef]

13. Li, J.; He, Z.B.; Du, J.; Chen, L.F.; Lin, P.F.; Zhu, X.; Fang, S.; Zhao, M.M.; Tian, Q.Y. Effects of winter irrigation on soil hydro-thermal features in desert oasis farmland in arid area during freezing and thawing period. Trans. Chin. Soc. Agric. Eng. (Trans. CSAE) 2018, 34, 105-112.

14. Firth, A.G.; Baker, B.H.; Brooks, J.P.; Smith, R.; Iglay, R.B.; Davis, J.B. Low external input sustainable agriculture: Winter flooding in rice fields increases bird use, fecal matter and soil health, reducing fertilizer requirements. Agric. Ecosyst. Environ. 2020, 300, 106962. [CrossRef]

15. Nira; Miura. Rice yield and soil fertility of an organic paddy system with winter flooding. Soil Sci. Plant Nutr. 2019, 65, 1-9.

16. Mu, H.C.; Wang, Z.H.; Chen, X.Q.; LI, W.H. The Characteristics of Soil Water and Salinity Distribution under Different Winter Irrigation Methods in the Northern Xinjiang Cotton Fields are Suitable for Irrigation. Acta Agric. Boreali Sin. 2017, 32, 319-324.

17. Yang, P.N.; Zia-Khan, S.M.L.; Wei, G.H.; Zhong, R.S.; Aguila, M. Winter Irrigation Effects in Cotton Fields in Arid Inland Irrigated Areas in the North of the Tarim Basin, China. Water 2016, 8, 47. [CrossRef]

18. Liu, Z.P.; Jiao, X.Y.; Lu, S.H.; Zhu, C.L.; Zhai, Y.M.; Guo, W.H. Effects of winter irrigation on soil salinity and jujube growth in arid regions. PLoS ONE 2019, 14, 6. [CrossRef]

19. Sun, S.M.; An, Q.X. Studies on the Effect of Winter Irrigation on Salt Movement in Tarim Irrigation Area. Xinjiang Farml. Reclam. Sci. Technol. 2009, 32, 40-41.

20. Yao, B.L. Study on Rules and Regulation of Soil Water-Heat-Salt Spatiotemporal Transfer Under No Winter and Spring Irrigation Cotton Fields in South Xinjiang. Ph.D. Thesis, China Agricultural University, Beijing, China, 2017.

21. Shi, H.B.; Li, D.P.; Yang, S.Q. Theoretical Study on Water, Heat and Salt Migration and Water Saving Irrigation in Saline Soil; China Water Power Press: Beijing, China, 2011.

22. Li, W.H.; Wang, Z.H.; Zheng, X.R.; Zhang, J.Z. Effects of freezing and thawing on soil salinity in cotton fields by long-term drip irrigation of saline-alkaline soil in North Xinjiang. Agric. Res. Arid Areas 2015, 33, 40-46.

23. Yao, B.L.; Li, G.Y.; Wang, F. Effects of winter irrigation and soil surface mulching during freezing-thawing period on soil water-heat-salt for cotton fields in south Xinjiang. Trans. Chin. Soc. Agric. Eng. (Trans. CSAE) 2016, 32, 114-120.

24. Lu, Z.; Xian, S.H.; Yao, H.L.; Fang, R.; She, J.B. Influence of freeze-thaw cycles in the presence of a supplementary water supply on mechanical properties of compacted soil. Cold Reg. Sci. Technol. 2019, 157, 42-52. [CrossRef]

25. Larson, L.L.; Kiemnec, G.L.; Johnson, D.E. Influence of Freeze-Thaw Cycle on Silt Loam Soil in Sagebrush Steppe of Northeastern Oregon. Rangel. Ecol. Manag. 2019, 72, 69-72. [CrossRef]

26. Bing, H.; He, P.; Zhang, Y. Cyclic freeze-thaw as a mechanism for water and salt migration in soil. Environ. Earth Sci. 2015, 74, 675-681. [CrossRef]

27. Fu, Q.; Li, T.N.; Li, T.X.; Cui, S. Influence of Straw Mulching on Soil Moisture Characteristics during Seasonal Freeze-thaw Period. Trans. Chin. Soc. Agric. Mach. 2015, 46, 141-146.

28. Lu, X.H.; Shi, H.B.; Li, R.P.; Liang, J.C.; Xu, Z.; Bu, H.L. NMR-based Research on Unfrozen Water and Pore Water in Salted. J. Soil Water Conserv. 2017, 31, 111-116.

29. Chen, H.R.; Peng, Z.Y.; Zeng, W.Z.; Wu, J.W. Salt Movement during Soil Freezing Events in Inner Mongolia, China. J. Coast. Res. 2018, 82, 55-63.

30. Wu, M.S.; Huang, J.S.; Wu, J.W.; Tan, X.; Jansson, P.E. Experimental study on evaporation from seasonally frozen soils under various water, solute and groundwater conditions in Inner Mongolia, China. J. Hydrol. 2016, 535, 46-53. [CrossRef]

31. Cui, L.H.; Zhu, Y.; Zhao, T.X.; Yang, J.Z.; Wu, J.W. Soil ion components and soil salts transport in frozen layer in seasonal freezing-thawing areas. Trans. Chin. Soc. Agric. Eng. (Trans. CSAE) 2019, 35, 75-82.

32. Xiao, Y.Q.; Yang, P.N.; Wu, B.; Liu, J.; Guo, T. Analysis of Arid Oasis Areas Soil Nitrogen Accumulation and Winter Irrigation Effect. Water Sav. Irrig. 2018, 2, 17. 
33. Zhang, H.; Yang, P.N.; Wang, C.S.; Li, X.Z. Effect of Winter Irrigation Amount on Soil Moisture and Salt Distribution in Arid Area. J. Irrig. Drain. 2016, 35, 42-46.

34. Li, Z.G.; Ye, H.C.; Xiao, R. Influence of Less \& Free Effect of Winter and Spring Irrigation on Soil Water and Salt Distribution in Cotton Non-Growth Period. Water Sav. Irrig. 2014, 12, 10-15.

35. Chen, X.Q.; Wang, Z.H.; He, X.L.; Li, W.H.; Jiang, G.J. Effects of Winter Irrigation Methods on Soil Moisture, Salt and Temperature Distribution in Cotton Fields in North Xinjiang. J. Soil Water Conserv. 2014, 28, $132-137$.

36. Tatiana, C.A.; Simone, R.d.S.; Sérgio, F.A.; Bruna, d.A.B.; Edypol, G.B.; Ligia, B.M. Water status and productivity of 'Hass' avocado trees in response to supplemental irrigation during winter. Pesquisa Agropecuária Brasileira 2019, 54.

37. Ma, W.G.; Hu, X.T.; Zhou, S.W.; Wang, W.E.; Ran, H. Winter Irrigation Effect and Its Variation with Time under Different Irrigation Quotas. Water Sav. Irrig. 2019, 2, 47-50.

38. Zhao, B.; Wang, Z.H.; Li, W.H. Effects of winter drip irrigation mode and quota on water and salt distribution in cotton field soil and cotton growth next year in northern Xinjiang. Trans. Chin. Soc. Agric. Eng. (Trans. CSAE) 2016, 32, 139-148.

(C) 2020 by the authors. Licensee MDPI, Basel, Switzerland. This article is an open access article distributed under the terms and conditions of the Creative Commons Attribution (CC BY) license (http://creativecommons.org/licenses/by/4.0/). 